ARTICLE

https://doi.org/10.1038/s41467-019-10661-8

\title{
Quantification of epitope abundance reveals the effect of direct and cross-presentation on influenza CTL responses
}

Ting $\mathrm{Wu}^{1,8}$, Jing Guan ${ }^{1,8}$, Andreas Handel ${ }^{2}$, David C. Tscharke (D) ${ }^{3}$, John Sidney ${ }^{4}$, Alessandro Sette ${ }^{4,5}$, Linda M. Wakim ${ }^{6}$, Xavier Y.X. Sng ${ }^{1}$, Paul G. Thomas (1) ${ }^{7}$, Nathan P. Croft (10) ${ }^{1}$, Anthony W. Purcell (1) ${ }^{1} \&$ Nicole L. La Gruta',

The magnitude of $T$ cell responses to infection is a function of the naïve $T$ cell repertoire combined with the context and duration of antigen presentation. Using mass spectrometry, we identify and quantify 21 class 1 MHC-restricted influenza A virus (IAV)-peptides following either direct or cross-presentation. All these peptides, including seven novel epitopes, elicit $T$ cell responses in infected C57BL/6 mice. Directly presented IAV epitopes maintain their relative abundance across distinct cell types and reveal a broad range of epitope abundances. In contrast, cross-presented epitopes are more uniform in abundance. We observe a clear disparity in the abundance of the two key immunodominant IAV antigens, wherein direct infection drives optimal nucleoprotein (NP) $366-374$ presentation, while cross-presentation is optimal for acid polymerase $(\mathrm{PA})_{224-233}$ presentation. The study demonstrates how assessment of epitope abundance in both modes of antigen presentation is necessary to fully understand the immunogenicity and response magnitude to $T$ cell epitopes.

\footnotetext{
${ }^{1}$ Monash Biomedicine Discovery Institute and Department of Biochemistry and Molecular Biology, Monash University, Clayton, VIC 3800, Australia. ${ }^{2}$ Department of Epidemiology and Biostatistics, Health Informatics Institute and Center for the Ecology of Infectious Diseases, University of Georgia, Athens, GA 30602, USA. ${ }^{3}$ John Curtin School of Medical Research, The Australian National University, Canberra, ACT 2601, Australia. ${ }^{4}$ Division of Vaccine Discovery, La Jolla Institute for Allergy and Immunology, La Jolla, CA, 92037, USA. ${ }^{5}$ Department of Medicine, University of California San Diego, La Jolla, CA, 92093, USA. ${ }^{6}$ Department of Microbiology and Immunology, The Peter Doherty Institute for Infection and Immunity, University of Melbourne, Melbourne, VIC 3000, Australia. ${ }^{7}$ Department of Immunology, St Jude Children's Research Hospital, Memphis, TN 38105, USA. ${ }^{8}$ These authors contributed equally: Ting Wu, Jing Guan. Correspondence and requests for materials should be addressed to N.P.C. (email: nathan.croft@monash.edu) or to A.W.P. (email: anthony.purcell@monash.edu) or to N. Gruta. (email: nicole.la.gruta@monash.edu)
} 
C $\mathrm{TL}$ responses are a critical determinant of protection against a number of diseases and there is a recognized need to develop vaccines that more effectively elicit $\mathrm{CD} 8^{+}$ $\mathrm{T}$-cell immunity. The optimum design of any T-cell-based vaccine mandates a comprehensive understanding of the factors that govern peptide immunogenicity and the size of the immune response. It is likely that the context and differential abundance of epitopes presented by MHCI molecules plays a critical role in driving the reproducible CTL response hierarchies observed in MHC-matched individuals, especially during natural infection. Certainly, indirect analyses indicate antigen abundance plays a key role-alteration of epitope context or dose (or both) within a pathogen, for example, has the capacity to alter the size of the corresponding T-cell response ${ }^{1,2}$. Our appreciation of the impact of epitope abundance on antigenicity and CTL response magnitude has, until recently, been limited by a lack of sufficiently sensitive methodologies to accurately and specifically probe this parameter $^{3}$. It is further complicated by the fact that MHCIrestricted epitopes may be presented by either directly infected cells or by professional antigen-presenting cells that take up infected material and exogenous viral antigens (cross-presentation). Each pathway may drive distinct epitope presentation characteristics for T-cell priming and expansion, yet the breadth and context of epitope abundance has not been studied systematically. Consequently, the question of how epitope abundance contributes to the immunogenicity and immunodominance of virus-derived $\mathrm{CD}^{+}$T-cell epitopes remains poorly understood ${ }^{4,5}$.

IAV infection of C57BL/6 (H-2 $\left.{ }^{b}\right)$ mice elicits a CTL immunodominance hierarchy, with reproducibly large (immunodominant) responses directed towards the $\mathrm{H}-2 \mathrm{D}^{\mathrm{b}}$-restricted epitopes $\mathrm{NP}_{366-374}$ and $\mathrm{PA}_{224-233}$, with all other detectable responses, including those directed toward $\mathrm{D}^{\mathrm{b} P B 1-F} 2_{62-70}, \mathrm{~K}^{\mathrm{b} P B} 1_{703-711}$, $\mathrm{K}^{\mathrm{b}} \mathrm{NS} 2_{114-121}$, and $\mathrm{K}^{\mathrm{b}} \mathrm{M} 1_{128-135}$ eliciting smaller (subdominant) responses ${ }^{1,6}$. Using an in vitro mass spectrometry-based strategy to identify and quantitate naturally processed $\mathrm{H}-2^{\mathrm{b}}$-restricted peptides, we identify 21 IAV-derived peptides following both direct infection and cross-presentation. These include seven novel peptides, presented by $\mathrm{H}-2 \mathrm{D}^{\mathrm{b}}$ and $\mathrm{H}-2 \mathrm{~K}^{\mathrm{b}}$. All identified peptides are able to elicit $\mathrm{CD} 8^{+} \mathrm{T}$-cell responses following infection, indicating that epitope presentation following in vitro infection is representative of that during in vivo infection. MHCI-associated peptide abundance following direct infection is significantly correlated between dendritic cell (DC) and lung epithelial cells, reflecting conserved viral antigen expression and processing during infection across different cell types. Strikingly, the relative abundance of peptides presented following direct and crosspresentation highlights a remarkable disparity between the two immunodominant epitopes despite most peptides showing an overall correlation. Notably, the $\mathrm{PA}_{224-233}$ peptide is much better presented via cross-presentation, while the $\mathrm{NP}_{366-374}$ peptide is optimally presented following direct infection. The addition of quantitative MS data from directly infected cells and crosspresented viral antigen is used along with other variables (naïve T-cell precursor frequency, MHCI-binding affinity, protein abundance) to model the drivers of T-cell response magnitude to IAV. This analysis indicates significant contributions of both direct and cross-presentation, as well as peptide affinity for $\mathrm{MHCI}$, in establishing the IAV-specific $\mathrm{CD}^{+}{ }^{+} \mathrm{T}$-cell immunodominance hierarchy.

\section{Results}

Identification and quantitation of MHCI-bound IAV peptides. Although a number of CD8 ${ }^{+}$T-cell epitopes have been identified in the B6 model of IAV infection ${ }^{7-9}$ (Table 1), their identification has been predominantly achieved through epitope prediction and screening of T-cell responses. To define a more complete spectrum of MHCI-bound IAV-derived peptides presented following infection, we employed a conventional mass spectrometry approach (LC-MS/MS) to detect $\mathrm{H}-2 \mathrm{D}^{\mathrm{b}}$ - and $\mathrm{H}-2 \mathrm{~K}^{\mathrm{b}}$-bound viral peptides following in vitro infection of DC2.4 cells ${ }^{10}$. Infected DC2.4 cells were harvested and lysed at $8 \mathrm{~h}$ post infection (hpi), peptide-MHCI complexes (pMHCI) were isolated, and peptides analyzed by LC-MS (Supplementary Data 1). A total of 21 IAVderived MHCI-bound peptides were identified. These included the $\mathrm{NP}_{366-374}\left[\mathrm{D}^{\mathrm{b}}\right], \mathrm{PA}_{244-233}\left[\mathrm{D}^{\mathrm{b}}\right], \mathrm{NS}_{114-121}\left[\mathrm{~K}^{\mathrm{b}}\right], \mathrm{PB}_{703-711}$ $\left[\mathrm{K}^{\mathrm{b}}\right]$ and $\mathrm{PB} 1-\mathrm{F} 2_{62-70}\left[\mathrm{D}^{\mathrm{b}}\right]$ peptides to which $\mathrm{T}$-cell responses have been extensively characterized ${ }^{1,6}$, and seven novel peptides that had not been previously reported (Table 1). Of these novel peptides, three were derived from the HA protein, two from the M1 protein, and one each from NA and NS2. HA $\mathrm{HA}_{41-49}$ (VTVTHSVNL) was detected in both $\mathrm{K}^{\mathrm{b}}$ and $\mathrm{D}^{\mathrm{b}}$ eluates, indicating that this peptide is a promiscuous binder, whilst $\mathrm{NS}_{8-16}$ was the only novel $\mathrm{K}^{\mathrm{b}}$-binder (Table 1 ). Although mouse MHCI $\mathrm{K}^{\mathrm{b}}$ and $\mathrm{D}^{\mathrm{b}}$ molecules typically bind peptides of 8-10 aa in length, three of the seven newly identified peptides were 11 aa long. The length of the newly identified peptides likely contributed to their obscurity to date since previous publication of a widely tested potential repertoire of IAV-derived epitopes generated via a matrix-based algorithm, assumed lengths of 8 aa for $\mathrm{K}^{\mathrm{b}}$ binders and $9-10$ aa for $\mathrm{D}^{\mathrm{b}}$ binders ${ }^{9}$. In summary, this screening process culminated in the identification of 21 IAV peptides presented by either $\mathrm{H}-2 \mathrm{~K}^{\mathrm{b}}$ or $\mathrm{H}-2 \mathrm{D}^{\mathrm{b}}$ (or both for $\mathrm{HA}_{41-49}$ ), including all of the well-characterized epitopes known to elicit $\mathrm{CD}^{+} \mathrm{T}$-cell responses.

Quantitation of directly presented IAV peptides. Having established the detectable repertoire of IAV peptides directly presented by DC2.4 cells at $8 \mathrm{hpi}$, we next quantitated the abundance of each peptide. The IAV peptides isolated from $\mathrm{H}$ $2 \mathrm{D}^{\mathrm{b}}$ and $\mathrm{K}^{\mathrm{b}}$ molecules were quantitated using an LC-MRM (liquid chromatography-multiple reaction monitoring) approach as previously reported for other viral epitopes ${ }^{4}$ (Supplementary Data 2). Stable isotope-labeled viral peptides were synthesized and LC-MRM parameters individually optimized for each peptide to provide a complete suite of internal quantitative standards (see Table 1, Supplementary Tables 1-3, and Supplementary Figs. 1 and 2). The abundance of the $21 \mathrm{IAV}$-derived peptides spanned three orders of magnitude, ranging from 1-2 copies/cell of $\mathrm{PB}_{653-660}$ to an average of 3871 copies/cell of $\mathrm{NP}_{366-374}$ (Fig. 1a). Of the well-characterized $\mathrm{CD}^{+}{ }^{-} \mathrm{T}$-cell epitopes, the immunodominant $\mathrm{NP}_{366-374}$ and subdominant $\mathrm{NS}_{114-121}$ peptides were the most abundant, being present at an average of 3871 and 2464 copies/cell, respectively, while the subdominant epitopes PB1$\mathrm{F} 2_{62-70}$ and $\mathrm{PB1}_{703-711}$ were substantially lower at 684 and 294 copies/cell, respectively. One of the least abundantly presented species was the immunodominant epitope $\mathrm{PA}_{224-233}$, at only 7 copies/cell. Thus, the abundance of peptides presented following direct infection of the DC2.4 cells did not predict the CTL immunodominance hierarchy.

Given that productive IAV infection is restricted to respiratory epithelial cells, which are also the targets of the IAV-specific CTL response, we next investigated the relative abundance of IAVderived peptides presented on $\mathrm{H}-2 \mathrm{D}^{\mathrm{b}}$ and $\mathrm{K}^{\mathrm{b}}$ molecules expressed on the surface of an infected lung epithelial cell line (LET1 cells) ${ }^{11}$ (Supplementary Data 2). Although the infection efficiency of LET1 cells was similar to DC2.4 cells ( 80-85\%) (Supplementary Fig. 3a), the expression of surface $\mathrm{H}-2 \mathrm{~K}^{\mathrm{b}}$ and $\mathrm{D}^{\mathrm{b}}$ complexes was lower in LET1 cells (Supplementary Fig. 3b), resulting in an overall reduction in the yield of peptides/cell (Fig. 1b). However, 


\begin{tabular}{|c|c|c|c|c|}
\hline Peptide & Sequence & Length (aa) & Allele & Citation \\
\hline$N P_{36-43}$ & IGRFYIQM & 8 & $\mathrm{~K}^{\mathrm{b}}$ & 9 \\
\hline $\mathrm{NP}_{55-63}$ & RLIQNSLTI & 9 & $D^{b}$ & 70 \\
\hline $\mathrm{NP}_{366-374}$ & ASNENMETM & 9 & $D^{b}$ & 71 \\
\hline $\mathrm{PA}_{224-233}$ & SSLENFRAYV & 10 & $\mathrm{D}^{\mathrm{b}}$ & 72 \\
\hline $\mathrm{PB1} 1_{653-660}$ & KNMEYDAV & 8 & $\mathrm{~K}^{\mathrm{b}}$ & 9 \\
\hline $\mathrm{PB1}_{703-711}$ & SSYRRPVGI & 9 & $\mathrm{~K}^{\mathrm{b}}$ & 73 \\
\hline PB1-F2 $62-70$ & LSLRNPILV & 9 & $\mathrm{D}^{\mathrm{b}}$ & 74 \\
\hline PB2 $227-234$ & VYIEVLHL & 8 & $\mathrm{~K}^{\mathrm{b}}$ & 7 \\
\hline NS2 $8-16$ & SFQDILLRM & 9 & $\mathbf{K}^{\mathbf{b}}$ & \\
\hline NS2 $114-121$ & RTFSFQLI & 8 & $\mathrm{~K}^{\mathrm{b}}$ & 7 \\
\hline$M 1_{128-135}$ & MGLIYNRM & 8 & $\mathrm{~K}^{\mathrm{b}}$ & 7 \\
\hline $\mathbf{M 1}_{207-216}$ & SQARQMVQAM & 10 & $\mathbf{D}^{\mathbf{b}}$ & \\
\hline $\mathrm{M1}_{227-237}$ & AGLKNDLLENL & 11 & $\mathbf{D}^{\mathbf{b}}$ & \\
\hline$H_{41-49}$ & VTVTHSVNL & 9 & $\mathbf{D}^{\mathbf{b}}$ & \\
\hline$H_{41-49}$ & VTVTHSVNL & 9 & $\mathbf{K}^{\mathbf{b}}$ & \\
\hline $\mathrm{HA}_{304-311}$ & SSLPYQNI & 8 & $\mathrm{~K}^{\mathrm{b}}$ & 8 \\
\hline$H_{308-316}$ & YQNIHPVTI & 9 & $\mathbf{D}^{\mathbf{b}}$ & \\
\hline$H_{389-399}$ & NGITNKVNTVI & 11 & $\mathbf{D}^{\mathbf{b}}$ & \\
\hline $\mathrm{HA}_{402-409}$ & MNIQFTAV & 8 & $\mathrm{~K}^{\mathrm{b}}$ & 9 \\
\hline $\mathrm{NA}_{181-190}$ & SGPDNGAVAV & 10 & $\mathrm{D}^{\mathrm{b}}$ & 9 \\
\hline $\mathbf{N A}_{\mathbf{1 8 1 - 1 9 1}}$ & SGPDNGAVAVL & 11 & $\mathbf{D}^{\mathbf{b}}$ & \\
\hline
\end{tabular}

Sequences in bold represent novel epitopes identified in this study IAV influenza $A$ virus

there was a significant correlation $(\mathrm{RCC}=0.6327, p=0.0021)$ between the relative mean abundance of each of the peptides quantified from both cell lines (Fig. 1c). To determine how the relative abundance of peptides presented in the context of $\mathrm{H}-2 \mathrm{~K}^{\mathrm{b}}$ or $\mathrm{D}^{\mathrm{b}}$ molecules correlated with the relative amount of source protein present at $8 \mathrm{hpi}$, we determined relative protein abundance using label-free quantitation (LFQ) through analysis in Maxquant ${ }^{12}$. A Spearman's rank correlation test revealed no correlation between relative source protein abundance and peptide abundance, which was exemplified by the fact that multiple peptides derived from the same source protein (e.g. $\mathrm{NP}_{366-374}, \mathrm{NP}_{36-43}$, and $\mathrm{NP}_{55-63}$ ) showed remarkably different abundance profiles (Fig. 1d). Collectively, these data indicate that the relative abundance of IAV-derived peptides presented by MHCI following direct infection was conserved irrespective of the cell type infected. Moreover, the abundance of the source protein at $8 \mathrm{hpi}$ was a poor predictor of the relative level of MHCI presentation.

Kinetics of IAV peptide presentation after direct infection. Unlike members of the orthopoxvirus or herpesvirus genera, in which discrete early, intermediate and late waves of transcription are readily defined, IAV has a segmented RNA genome that is simultaneously transcribed and is therefore unlikely to show large variation in protein expression kinetics. To investigate whether IAV-derived peptide presentation was also temporally uniform, cell lysates were harvested from IAV-infected DC2.4 cells at various timepoints post infection and viral epitope abundance determined by LC-MRM (Fig. 2a and Supplementary Fig. 4 and Supplementary Data 2). Six of the 21 epitopes were detectable by $30 \mathrm{~min}$ after infection, including all three of the M1 peptides $\left(\mathrm{M1}_{128-135}, \mathrm{M1}_{207-216}, \mathrm{M1}_{227-237}\right)$, both of the NA peptides $\left(\mathrm{NA}_{181-190}, \mathrm{NA}_{181-191}\right)$, and one of the HA peptides $\left(\mathrm{HA}_{41-49}\right)$, indicating some preference for structural protein-derived peptides at this early timepoint. The majority of the remaining epitopes could be detected by $2.5 \mathrm{hpi}$, and all epitopes were detectable by $4.5 \mathrm{hpi}$. The subsequent kinetics of peptide presentation fell broadly into three categories: seven peptides whose presentation peaked at around $6.5 \mathrm{hpi}$ and gradually diminished thereafter (Fig. 2a, yellow), 12 peptides whose presentation peaked at around 9.5 hpi and subsequently diminished (Fig. 2a, red), and two peptides whose presentation was continuing to increase at $12.5 \mathrm{hpi}$ (Fig. 2a, blue). Neither of the immunodominant $\mathrm{NP}_{366-374}$ or $\mathrm{PA}_{224-233}$ epitopes showed a more rapid presentation kinetic than subdominant determinants, nor was there an association between duration of presentation and immunodominance, with $\mathrm{NP}_{366-374}$ presentation declining at 12.5h (Fig. 2a, dashed lines).

Given the suggestion that peptide presentation may be more closely associated with the rate of protein translation rather than steady-state protein amounts ${ }^{4,13}$, we determined the relationship between the kinetics of protein expression and peptide presentation. Antigen expression was detectable either prior to, or coincident with, the detection of presented peptide. Intriguingly, peak presentation of the majority of the peptides $(15 / 21)$ preceded the peak of protein abundance, while the peak of the seven remaining peptides was coincident with peak antigen expression (Fig. 2b). These observations corroborate studies suggesting proteasomal degradation of newly synthesized proteins is a prominent source of MHCI peptides ${ }^{14}$. Again, as for absolute abundance at $8 \mathrm{hpi}$, the kinetics of peptide presentation were not dictated by the protein source as peptides derived from the same protein exhibited distinct kinetics. Thus, the majority of peptides were optimally presented between 6.5 and $9.5 \mathrm{hpi}$ and the kinetics of epitope presentation occurred largely independently of antigen expression kinetics.

Identification and quantitation of cross-presented peptides. Cross-presentation has been implicated in the generation of CTL immunity during IAV infection ${ }^{15}$. Having established the abundance hierarchy of each of the IAV peptides following direct infection of both a DC and a lung epithelial cell line, we next sought to determine whether a similar or distinct peptide hierarchy was observed following cross-presentation.

To assess cross-presentation of IAV-derived peptides (Fig. 3a), MHCI $\mathrm{D}^{\mathrm{b}-} \mathrm{K}^{\mathrm{b}-}$ donor cells (human alveolar epithelial cell line, A549) were infected with IAV, irradiated and washed, and then incubated with a CpG-activated, cross-presenting MHCI $\mathrm{D}^{\mathrm{b}+} \mathrm{K}^{\mathrm{b}}$ + Mutu DC line ${ }^{16}$. Cross-presentation of IAV-derived peptides was confirmed using IAV engineered to express the ovalbuminderived SIINFEKL epitope ${ }^{17}$. Cross-presentation of the $\mathrm{K}^{\mathrm{b}}$-SIINFEKL epitope was detected both via cell surface staining of Mutu DCs with an antibody specific for the $\mathrm{K}^{\mathrm{b}}$-SIINFEKL complex (Supplementary Fig. 5a), as well as by division of OT-I cells following $48 \mathrm{~h}$ co-culture with cross-presenting Mutu DCs (Supplementary Fig. 5b).

Having established the in vitro cross-presentation system, the abundance of IAV-derived peptides presented via crosspresentation by Mutu DCs was determined by LC-MRM (Supplementary Data 2). Compared to directly presented peptides (Fig. 1a), the abundance of cross-presented peptides was substantially reduced (the most abundantly cross-presented peptide, $\mathrm{PB} 1_{703-711}$, was presented at an average of 39 copies/ cell, compared to 3871 copies/cell of the most abundant directly presented peptide, $\left.\mathrm{NP}_{366-374}\right)$. Moreover, the range of IAV epitope presentation spanned only two orders of magnitude (compared to three orders by direct presentation) (Supplementary Fig. 5c). Despite this, of the 21 peptides identified by direct presentation, 15 were also detected by cross-presentation. The epitope abundance hierarchy was normalized to the amount of $\mathrm{PB1}_{703-711}$ detected within each experiment (Fig. 3b). A significant correlation existed between the relative abundance of cross-presented versus directly presented peptides $(\mathrm{RCC}=$ 

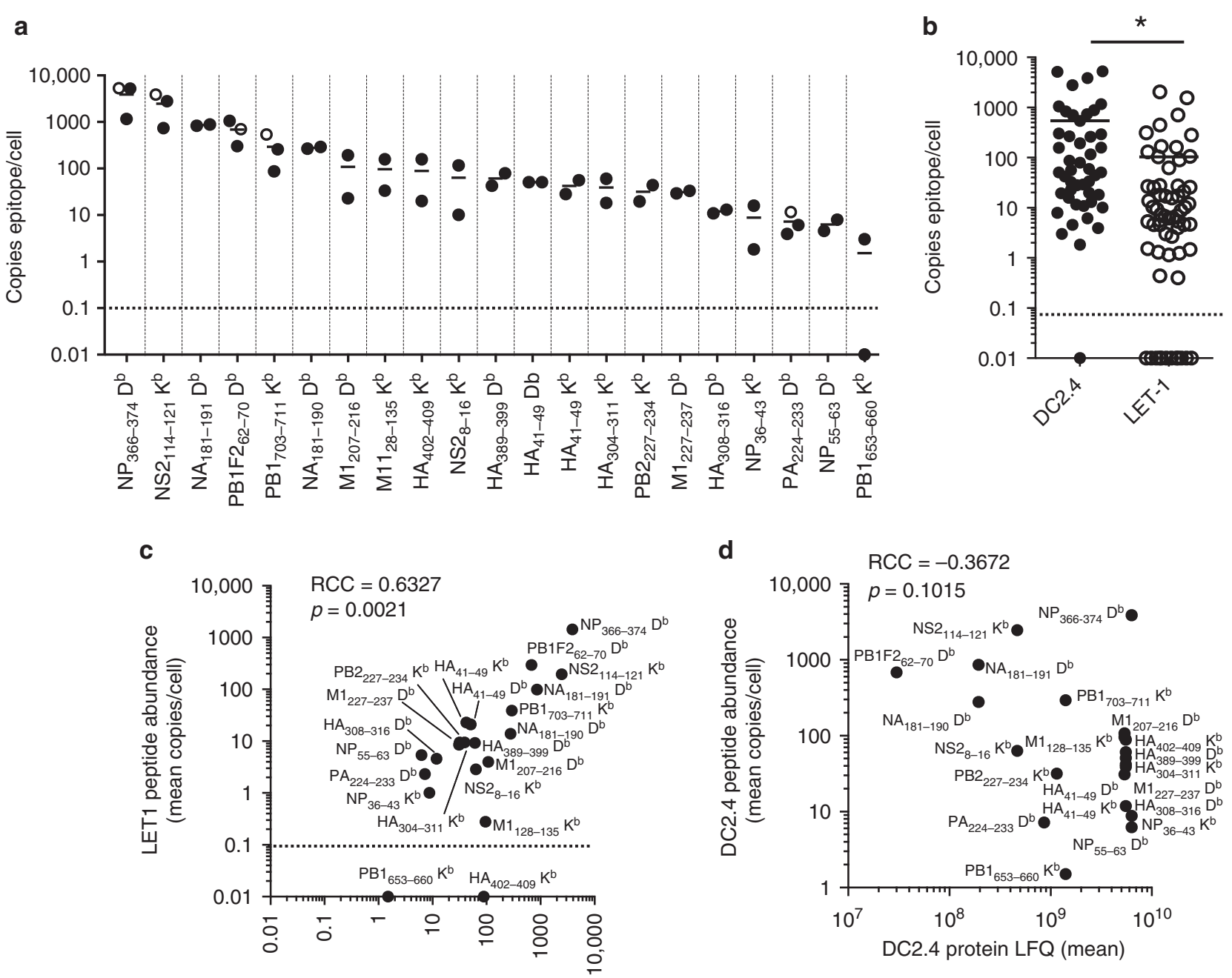

DC2.4 peptide abundance

(mean copies/cell)

Fig. 1 Detection and quantitation of $\mathrm{MHCl}$-bound IAV peptides following direct infection. DC2.4 cells $\left(1 \times 10^{8}\right)$ were mock treated or infected for $8 \mathrm{~h}$ with the PR8 strain of IAV at an MOI of 5, epitopes were eluted from immunoaffinity-purified $\mathrm{K}^{\mathrm{b}}$ and $\mathrm{D}^{\mathrm{b}} \mathrm{MHCl}$ molecules and analyzed by LC-MRM. a Absolute quantitation of peptide abundance shown as peptide copies/cell. $N=2-3$ independent infections are shown. Open circles represent initial quantitation of known epitopes. Closed circles represent quantitation of all epitopes discovered by LC-MS/MS. $\mathbf{b}$ Quantitation of peptides eluted from DC2.4 cells and LET1 cells, with each data point representing a single replicate of a particular peptide. $N=2-3$ independent infections ( ${ }^{*} p=0.008$ using Mann-Whitney nonparametric test). Correlation between $\mathbf{c}$ mean peptide abundance from DC2.4 cells vs. LET1 cells $(N=3)$, and $\mathbf{d}$ mean peptide vs. relative protein abundance in DC2.4 cells, showing the Spearman's rank correlation coefficient (RCC) and associated $p$ values. Dashed lines represent the limit of detection

0.6365, $p=0.0019$ ) (Supplementary Fig. 5d). However, there were some key outliers to this association. Most notably, the rank order of $\mathrm{PA}_{224-233}$ was substantially increased by cross-presentation such that it was one of the most abundantly cross-presented peptides (Fig. 3c). Given the overall lower efficiency of the crosspresentation system, these data suggest that $\mathrm{PA}_{224-233}$ is substantially more efficiently presented via cross- than direct presentation.

Measurement of peptide-MHCI binding strength. The strength of the noncovalent interaction between peptide and the binding groove of $\mathrm{MHC}$ has long been implicated in contributing to immunogenicity; however, the extent to which the affinity of this interaction ultimately impacts upon pMHCI abundance remains largely unknown ${ }^{18}$. To address the role of peptide binding affinity for MHCI in determining epitope abundance and CTL responses, for each of the peptides identified in this study we have determined peptide-MHC affinity $\left(\mathrm{IC}_{50} \mathrm{nM}\right)$ values experimentally using classical competition assays ${ }^{19}$ (Table 2). Overall, 17/20 $(85 \%)$ of the peptides bound either $\mathrm{H}-2 \mathrm{~K}^{\mathrm{b}}$ or $\mathrm{D}^{\mathrm{b}}$, or both with an affinity of $500 \mathrm{nM}$ or better, an affinity threshold identified for the vast majority of known class I epitopes ${ }^{20,21}$; ten peptides can be classified as strong binders $\left(\mathrm{IC}_{50}<50 \mathrm{nM}\right)$ for one or the other allele, seven as intermediate binders ( $\mathrm{IC}_{50}$ between 50 and 500 $\mathrm{nM}$ ), and three as weak ( $\mathrm{IC}_{50}$ between 500 and $5000 \mathrm{nM}$ ) or nonbinders $\left(\mathrm{IC}_{50}>5000 \mathrm{nM}\right)$. Surprisingly, there was no significant correlation between the strength of peptide binding, as defined by $\mathrm{IC}_{50}$, and epitope abundance measured following direct or cross-presentation (Fig. 4).

Characterization of $\mathrm{T}$-cell responses to the identified IAV peptides. The above data represent the first in-depth analysis of the differential abundance of virus peptides presented by MHC class I complexes via the routes of direct versus crosspresentation. In order to relate this information to the immunogenicity of each peptide in vivo, we systematically characterized 

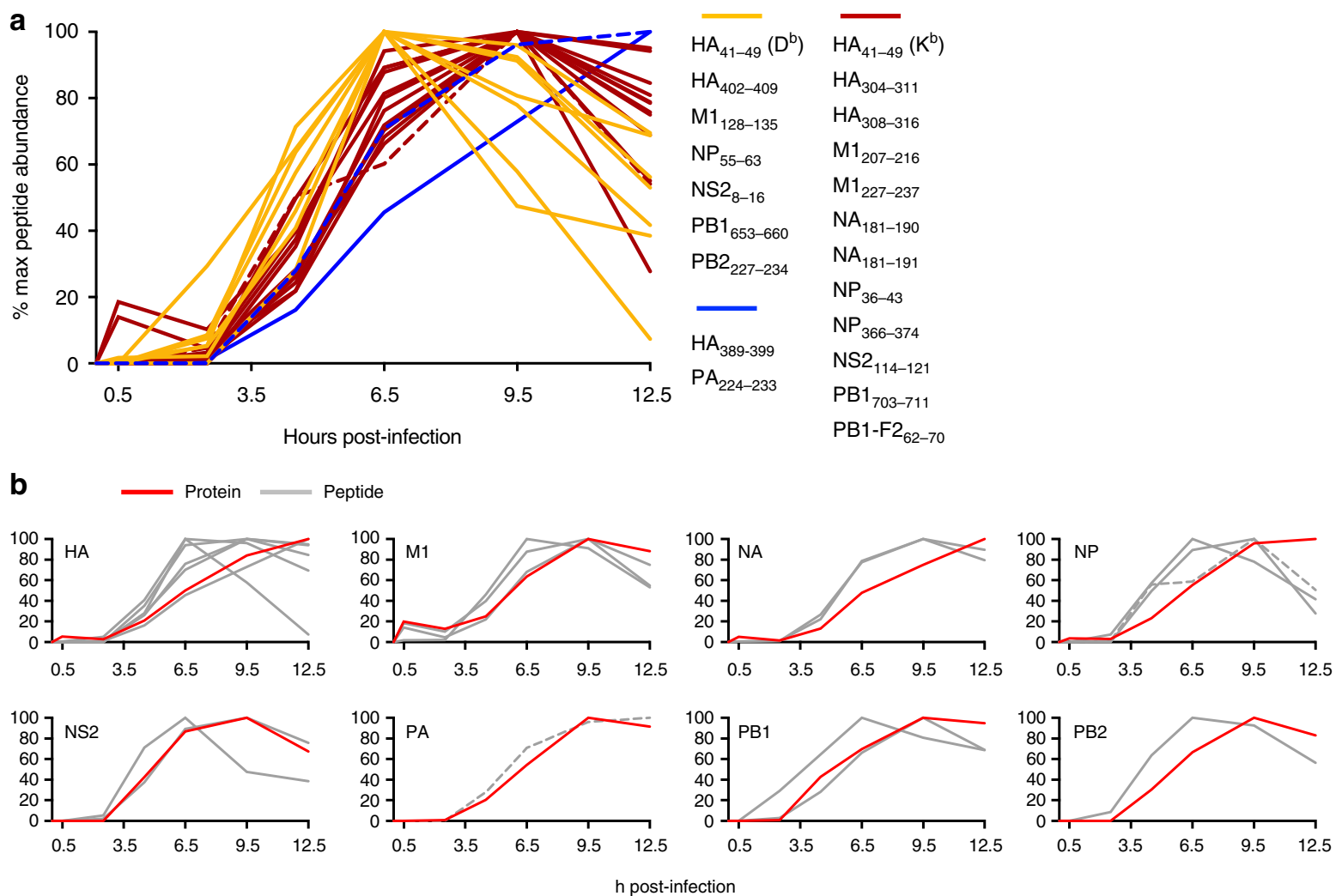

Fig. 2 Kinetics of protein expression and peptide presentation. a The kinetics of peptide presentation were determined by LC-MRM analysis of MHCIbound peptides isolated from infected DC2.4 cells at $0,0.5,2.5,6.5,9.5$ or $12.5 \mathrm{~h}$ post infection. Data are expressed as a percentage of maximum levels detected over the timecourse. Peptides whose abundance peaked at $6.5 \mathrm{~h}$ are shown in yellow, those that peaked at $9.5 \mathrm{~h}$ shown in red, and those that continued to increase at $12.5 \mathrm{~h}$ are shown in blue. b Relative peptide abundance (gray) is plotted alongside relative protein abundance (red) kinetics for the various IAV-derived proteins. Dashed lines indicate the immunodominant $\mathrm{NP}_{366-374}$ and $\mathrm{PA}_{224-233}$ peptides

the immune response elicited to each peptide identified in this study after IAV infection. The magnitudes of epitope-specific CTL responses, as defined by IFN- $\gamma$ production, were determined from spleen and bronchoalveolar lavage (BAL) 10 days after intranasal IAV infection of B6 mice (Fig. 5a and Supplementary Fig. 6). As shown previously, $\mathrm{D}^{\mathrm{b}} \mathrm{NP}_{366-374}$ and $\mathrm{D}^{\mathrm{b}} \mathrm{PA}_{224-233}$ elicited dominant $\mathrm{CD}^{+}{ }^{+}$-cell responses (comprising $~ 60 \%$ of the total antiviral response) (Fig. 5b, c) with all other epitopes eliciting smaller responses. Strikingly, all 20 of the peptides identified in the analysis (this assay cannot distinguish between $\mathrm{K}^{\mathrm{b}}$ - and $\mathrm{D}^{\mathrm{b}}$-restricted $\mathrm{HA}_{41-49}$-specific responses) were able to elicit a response in at least one mouse, with a consistent $\mathrm{CD}^{+} \mathrm{T}$-cell response (found in $\geq 3$ mice) detected toward 16 of the $20 \mathrm{IAV}$ peptides. These public responses included all seven welldocumented IAV-derived peptides $\left(\mathrm{D}^{\mathrm{b}} \mathrm{NP}_{366-374}, \mathrm{D}^{\mathrm{b}} \mathrm{PA}_{224-233}\right.$,

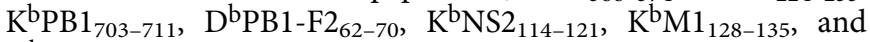
$\mathrm{D}^{\mathrm{b}} \mathrm{NA}_{181-190}$ ) (Fig. 5b), and a further nine peptides detected in this study. These data thus confirm that the peptides identified by mass spectrometry, despite being isolated from cells infected in vitro, are presented on MHCI during in vivo infection.

Collectively, $\mathrm{CD}^{+}{ }^{\mathrm{T}} \mathrm{T}$-cell responses to the seven novel epitopes identified in this study comprise $\sim 10 \%$ of the total antiviral response, as mapped thus far. Analysis of the frequency with which each peptide was able to elicit a response revealed a tendency for responses to be elicited in either a few individuals ( $\leq$ $3 / 11$ mice; 35\%) or in all mice (30\%) (Fig. 5d). Perhaps unsurprisingly, the frequency with which a peptide was able to induce a CTL response was positively correlated to the magnitude of that response (Fig. 5e). These data suggest that a threshold of immunogenicity exists, above which all mice are able to respond and below which the response is more stochastic.

Modeling of parameters that may impact T-cell response magnitude. Given that we have measured multiple variables that may contribute to CTL immunodominance, both in this study and earlier investigations $s^{2,22}$, and obtained an epitopebased hierarchy for each of these measures, we employed an integrated statistical and modeling approach to determine their relative contributions to the CTL immunodominance hierarchy. Initially, we investigated correlations between the outcome of CTL response for each epitope and all other epitope-specific variables. For each variable, we took the mean of repeated measurements for a given epitope and computed rank correlation between variables (Fig. 6a). As observed previously, for the five epitopes for which naive CTL precursors (CTLP) have been determined, there was a negative correlation between CTLp frequency and CTL responses after infection. Despite strong correlations in virus protein levels between DC2.4 and LET1 cells, protein abundance showed weak association with epitope abundance via direct or cross-presentation, nor did it correlate with CTL response magnitude. The variables found to be significantly positively associated with CTL response magnitude were the peptide abundances driven by each of the presentation pathways analyzed. Surprisingly, while $\mathrm{IC}_{50}$ showed a moderate correlation $(\mathrm{RCC}=-0.4)$ with the CTL response, it showed poor associations with all measures of epitope abundance. 
a

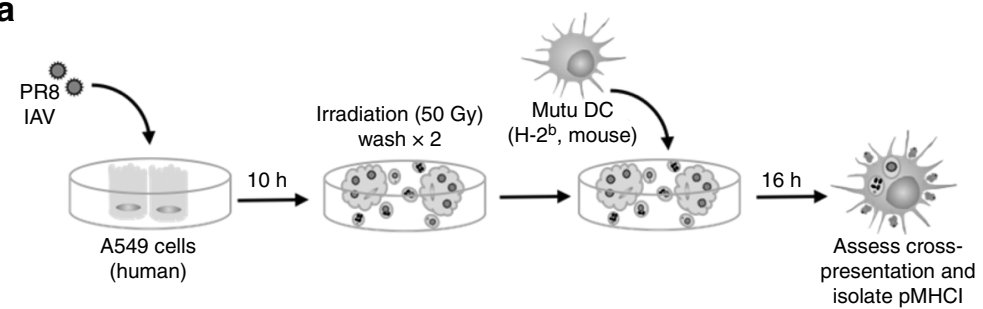

b

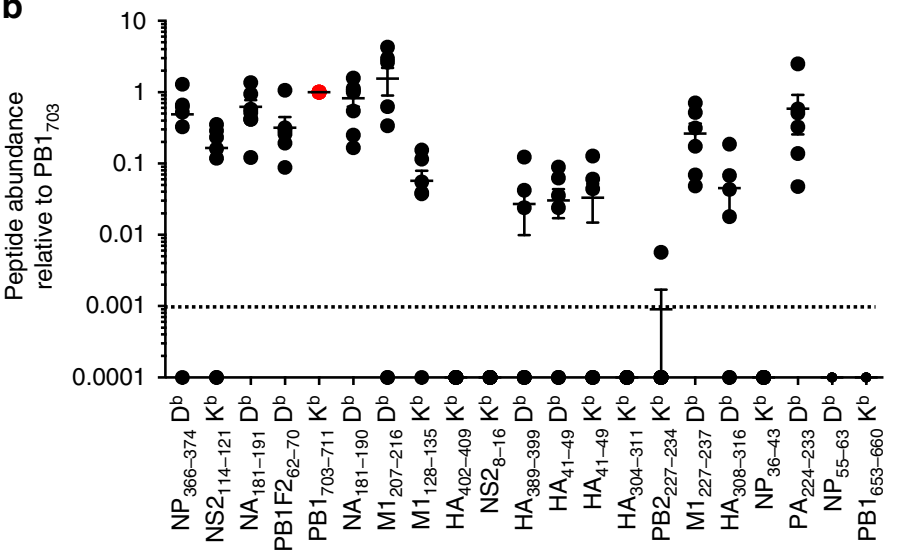

C

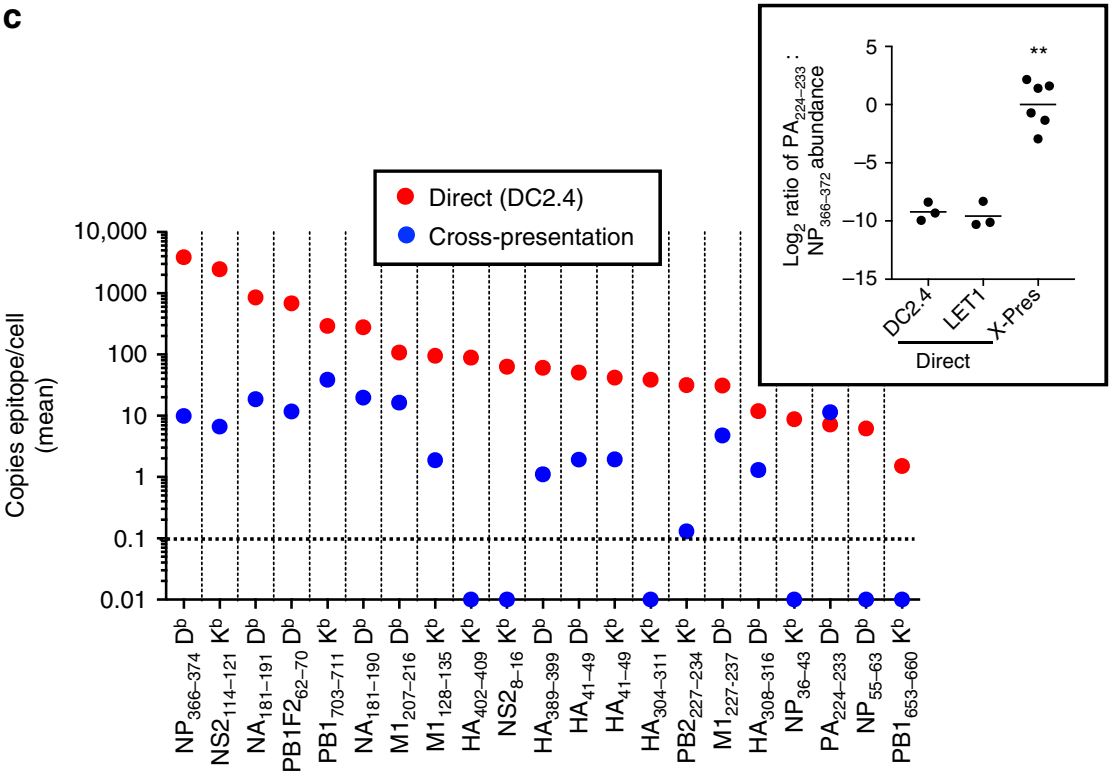

Fig. 3 Detection and quantitation of cross-presented IAV peptides. a Schematic of in vitro cross-presentation workflow. A549 cells ( $5 \times 10^{7}$ ) were infected for $10 \mathrm{~h}$ with PR8 IAV at an $\mathrm{MOI}$ of 10 . The A549 cells were then $\gamma$-irradiated (50 Gy) and co-incubated for $16 \mathrm{~h}$ with $5 \times 10^{7} \mathrm{Mutu}$ DCs. Epitopes were then eluted from immunoaffinity-purified $\mathrm{K}^{\mathrm{b}}$ and $\mathrm{D}^{\mathrm{b}} \mathrm{MHCl}$ molecules and analyzed by LC-MRM. b Shown is the mean relative abundance \pm SEM of each peptide compared to $\mathrm{PB}_{703-711}$ (in red) within the same experiment. c Absolute quantitation (mean epitope copies/cell shown) of peptide abundance following direct infection and cross-presentation. Direct epitope abundance shown in red circles while cross-presented epitope abundance shown in blue circles. Inset shows the ratio of $\log _{2}$ transformed $\mathrm{PA}_{224-233}: \mathrm{NP}_{366-374}$ epitope abundance for each of the different analyses of epitope presentation. $\mathrm{N}=7$ independent cross-presentation assays. ${ }^{* \star} p<0.0001$ comparing cross-presentation and direct (DC2.4) ratios, and cross-presentation and direct (LET1) ratios, using one-way ANOVA with Tukey post-hoc test

To investigate the relationship between the antiviral T-cell response and the different epitope-related quantities in more detail, we moved from an analysis of rank correlations to an analysis of actual numeric values for each variable. We performed simple linear regression to evaluate linear correlations on the log scale between CTL response and each individual predictor variable. This analysis showed linear correlations of epitope presentation (DC2.4 and LET1 direct presentation and crosspresentation) and T-cell response magnitude, and no correlation between T-cell response and protein levels. This analysis also found that peptide $\mathrm{IC}_{50}$ was significantly correlated with $\mathrm{T}$-cell response magnitudes (Fig. 6b).

These findings suggested that a multivariate linear model might further improve the ability to predict CTL magnitude. To test this, we used an exhaustive subset selection approach with crossvalidation to assess multivariate linear regression models with all possible combinations of variables to determine their ability to predict CTL magnitude, as quantified by $R^{2}$. Naïve CTLp 
frequency was excluded from this analysis due to the limited dataset. The best-performing model only included two variables: cross-presentation and $\mathrm{IC}_{50}$, and had a cross-validated $R^{2}$ of 0.68 (and an $R^{2}$ of 0.76 without cross-validation), indicating a substantial improvement over any individual predictor (Fig. 6b). Using a proportional marginal variance decomposition (PMVD) method, we found that around $66 \%$ of the relative importance was attributed to cross-presentation, with the remaining $34 \%$ attributed to $\mathrm{IC}_{50}$. This finding is in line with the univariate analysis shown in Fig. 6b, which identified cross-presentation as the strongest contributor to CTL response magnitude. While the direct presentation variables also showed strong correlation in the univariate analysis, they are strongly correlated with crosspresentation and are thus not selected by the model building routine.

Next, to investigate the role of each individual epitope, we performed the above analysis while withholding a different epitope from the data each time. For 19 of the 20 epitopes

\begin{tabular}{|c|c|c|}
\hline & $\mathbf{H - 2} \mathbf{D}^{\mathbf{b}}$ & $H-2 K^{b}$ \\
\hline $\mathrm{NP}_{36-43}$ & 3303 & 1.9 \\
\hline$N P_{55-63}$ & 184 & 463 \\
\hline $\mathrm{NP}_{366-374}$ & 18 & - \\
\hline $\mathrm{PA}_{224-233}$ & 0.16 & 38 \\
\hline $\mathrm{PB1}_{653-660}$ & - & 156 \\
\hline $\mathrm{PB1}_{703-711}$ & 28988 & 1.9 \\
\hline PB1-F2 $62-70$ & 18 & 12403 \\
\hline PB2 $227-234$ & 20903 & 2.8 \\
\hline $\mathrm{NS}_{8-16}$ & 10687 & 185 \\
\hline NS2 $2_{114-121}$ & - & 4.7 \\
\hline $\mathrm{M1}_{128-135}$ & - & 92.6 \\
\hline $\mathrm{M1}_{207-216}$ & 11225 & 26943 \\
\hline $\mathrm{M1}_{227-237}$ & 5285 & 3306 \\
\hline $\mathrm{HA}_{41-49}$ & 872 & 7.9 \\
\hline $\mathrm{HA}_{304-311}$ & - & 4.7 \\
\hline $\mathrm{HA}_{308-316}$ & 1971 & 1138 \\
\hline $\mathrm{HA}_{389-399}$ & 118 & 22004 \\
\hline $\mathrm{HA}_{402-409}$ & 6180 & 3.0 \\
\hline $\mathrm{HA}_{467-476}$ & 173 & - \\
\hline $\mathrm{NA}_{181-190}$ & 65 & 262 \\
\hline $\mathrm{NA}_{181-191}$ & 64 & 585 \\
\hline
\end{tabular}

removed, all best-fit models included the variables crosspresentation and $\mathrm{IC}_{50}$ as the factors that contributed the most to CTL response magnitudes. Intriguingly, removal of the $\mathrm{PA}_{224-233}$ epitope changed the best-fit model to one that included the DC2.4 direct presentation and the DC2.4 and LET1 protein level variables. Thus, it seems that cross-presentation is the major correlate for the $\mathrm{D}^{\mathrm{b}} \mathrm{PA}_{224-233}$-specific CTL response, and that its weighting as a superior global correlate (compared to direct presentation) for the CTL response was due to its influence on the $\mathrm{D}^{\mathrm{b}} \mathrm{PA}_{224-233^{-}}$-specific CTL response.

Finally, to determine if a model that allowed more complex relations (i.e. beyond linear) between CTL magnitude and epitope-specific variables would perform better, we applied a support vector machine model (SVM), a random forest (RF), and a gradient boosted regression tree model (GBM). We also used a LASSO method as an alternative way of doing variable selection for a linear model. However, none of these models provided better performance than the multivariate linear model (measured by cross-validated $R^{2}$ ) after tuning and training. Further details are provided in the Supplementary Methods. Thus, for the dataset analyzed here, cross-presentation and the $\mathrm{IC}_{50}$ variables additively determine T-cell response strength, with no further predictive strength gained from the other variables or from a more complicated model structure.

\section{Discussion}

Mass spectrometry analyses of the nature and abundance of IAVderived peptides presented on MHCI after infection identified 21 peptides (including seven novel epitopes), all of which were able to elicit $\mathrm{CD} 8^{+} \mathrm{T}$-cell responses after infection. Of the 21 peptides identified in this study, seven were 10-11 aa in length, including four of the seven novel peptides. Notably, all of these longer IAVderived peptides were bound by $\mathrm{H}-2 \mathrm{D}^{\mathrm{b}}$ while all seven of the shorter octamers were bound by $\mathrm{H}-2 \mathrm{~K}^{\mathrm{b}}$, consistent with previous observations that MHC alleles exhibit distinct peptide length preferences ${ }^{23,24}$. The identification of $10-11$ aa peptides is also consistent with the observation that a substantial proportion of naturally occurring mouse MHCI-bound peptides are longer than the canonical length of 8-9 aa. Such observations are becoming more apparent as global immunopeptidomics analyses increase ${ }^{18,25}$, and underscore the potential deficiencies in many predictive algorithms ${ }^{26}$. That long peptides from viruses and tumors are naturally processed and presented on MHCI suggests they likely play a key role in antiviral and antitumor immunity ${ }^{25}$. Long peptides have been found to be accommodated by MHCI
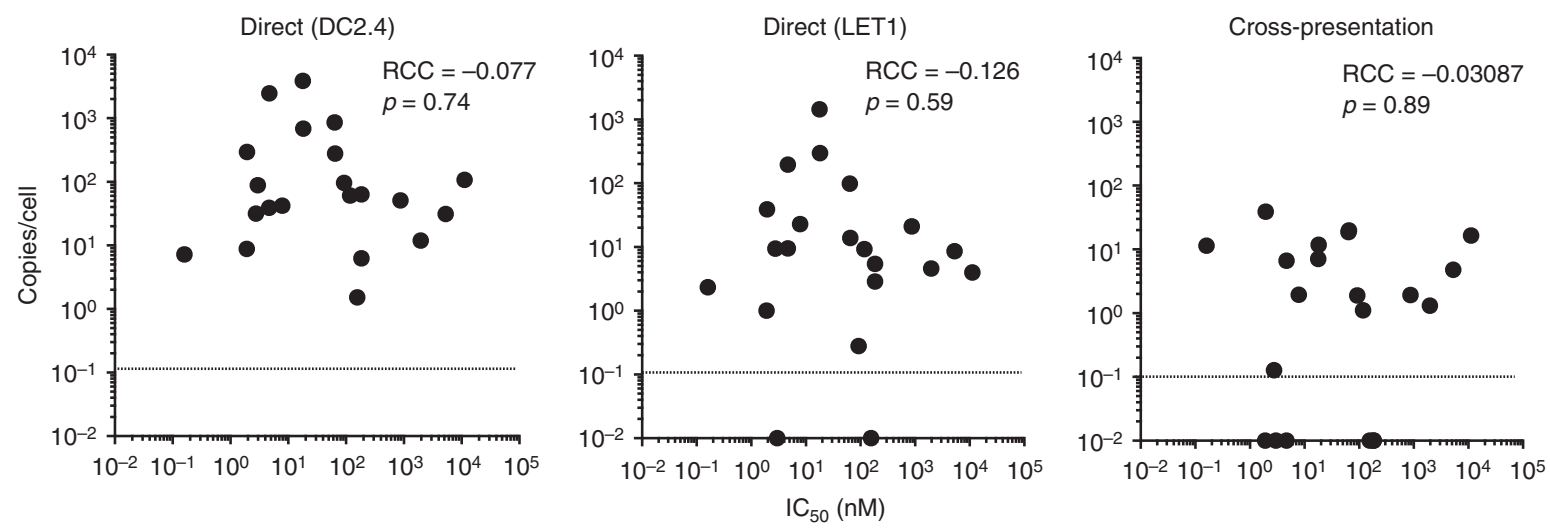

Fig. 4 Correlation of peptide- $\mathrm{MHCl}$ binding affinity and epitope abundance. The mean peptide abundance as determined following direct infection of DC2.4 cells or LET1 cells or via A549 $\times$ Mutu cross-presentation was correlated with the mean IC $_{50}$ of each bound peptide, showing the Spearman's rank correlation coefficient (RCC) and associated $p$ values 
a No peptide $\quad \mathrm{NP}_{366-374} \quad \mathrm{NS}_{114-121} \quad \mathrm{NA}_{181-191} \mathrm{PB1}-\mathrm{F} 2_{62-70} \mathrm{PB1} 1_{703-711} \quad \mathrm{NA}_{181-190} \quad \mathrm{M}_{207-216} \quad \mathrm{M}_{128-135} \quad \mathrm{HA}_{402-409} \quad \mathrm{NS}_{8-16}$
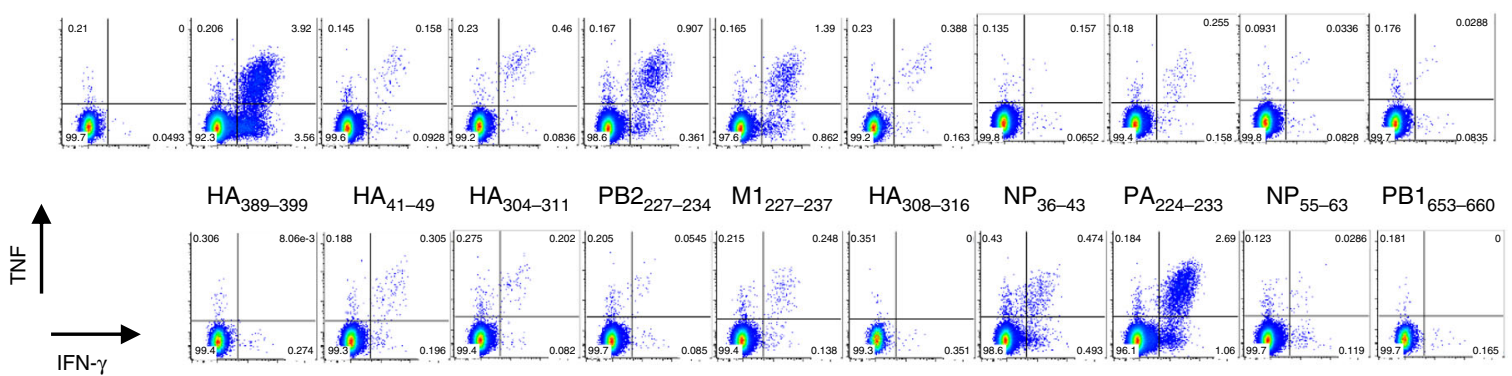

b

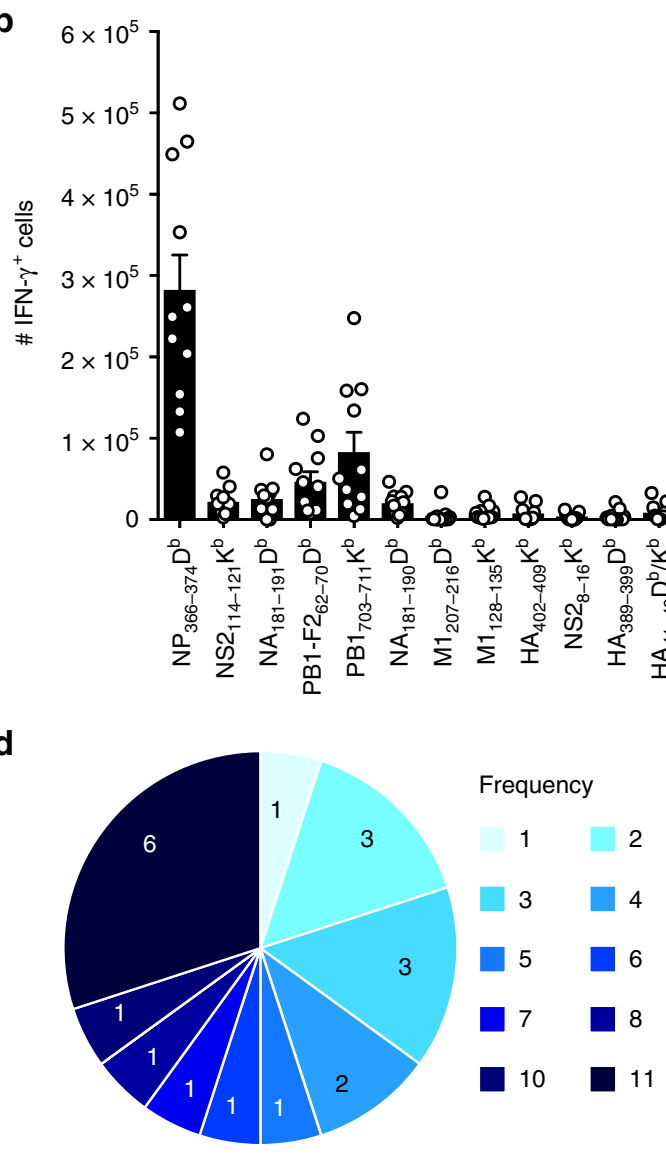

\section{d}

C

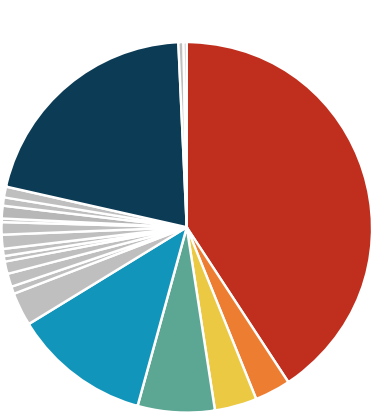

$\mathrm{NP}_{366-374} \mathrm{D}^{\mathrm{b}}$

NS2 ${ }_{114-121} K^{b}$

$\mathrm{NA}_{181-191} \mathrm{D}^{\mathrm{b}}$

$\mathrm{PB} 1-\mathrm{F} 2_{62-70} \mathrm{D}^{\mathrm{b}}$

- PB1 ${ }_{703-711} \mathrm{~K}^{\mathrm{b}}$

- $N A_{181-190} D^{b}$

- $M 1_{207-216} \mathrm{D}^{\mathrm{b}}$

- $\mathrm{M}_{128-135} \mathrm{~K}^{\mathrm{b}}$

$\mathrm{HA}_{402-409} \mathrm{~K}^{\mathrm{b}}$

$\mathrm{NS}_{8-16} \mathrm{~K}^{\mathrm{b}}$

- $\mathrm{HA}_{389-399} \mathrm{D}^{\mathrm{b}}$

$\mathrm{HA}_{41-49} \mathrm{D}^{\mathrm{b}} / \mathrm{K}^{\mathrm{b}}$

$\mathrm{HA}_{304-311} \mathrm{~K}^{\mathrm{b}}$

- PB2 $227-234 \mathrm{~K}^{\mathrm{b}}$

M1 $1_{227-237} \mathrm{D}^{\mathrm{b}}$

$\mathrm{HA}_{308-316} \mathrm{D}^{\mathrm{b}}$

$\mathrm{NP}_{36-43} \mathrm{~K}^{\mathrm{b}}$

- $\mathrm{PA}_{224-233} \mathrm{D}^{\mathrm{b}}$

-1 $\mathrm{NP}_{55-63} \mathrm{D}^{\mathrm{b}}$

- $\mathrm{PB} 1{ }_{653-660} \mathrm{~K}^{\mathrm{b}}$

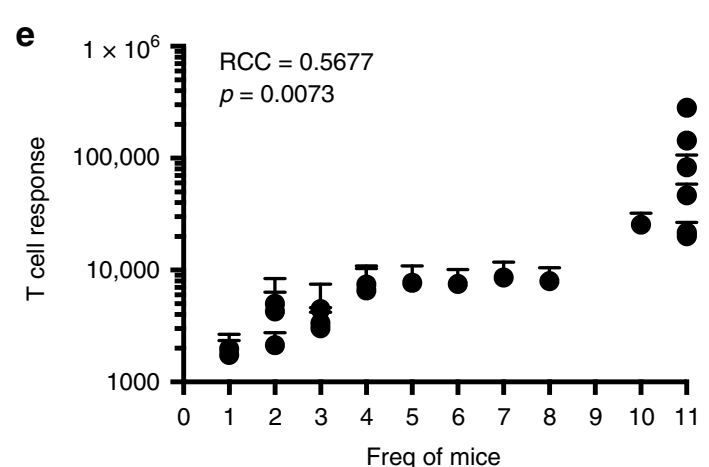

Fig. 5 Analysis of primary CD8 ${ }^{+}$T-cell responses to IAV-derived peptides. Naive B6 mice were infected i.n. with 1000 pfu PR8 IAV, and spleens harvested 10 days later. Splenocytes, enriched for $\mathrm{CD}^{+} \mathrm{T}$ cells, were stimulated for $5 \mathrm{~h}$ in the presence or absence of $1 \mu \mathrm{M}$ of individual peptides, and analyzed by intracellular staining for the production of IFN- $\gamma$ and TNF. a Representative dot plots of CD8 ${ }^{+}$T-cell production of IFN- $\gamma$ and TNF following peptide restimulation. Values indicate the percentage of $\mathrm{CD}^{+}$cells within each gate. $\mathbf{b}$ Number of splenic $\mathrm{CD} 8^{+}$IFN- $\gamma^{+}$cells responding to each peptide from 11 mice in two independent experiments \pm SEM. c Relative contribution of each detectable epitope-specific CD8 ${ }^{+} \mathrm{T}$-cell response to the total detectable response. $\mathbf{d}$ Frequency (out of a total of 11 mice) with which the identified peptides are able to elicit CD8 ${ }^{+}$T-cell responses. Numbers within pie chart indicate number of peptides. e The mean $+\mathrm{SEM} \mathrm{CD} 8^{+} \mathrm{T}$-cell response plotted against the cumulative number of mice in which the responses were detected. $N=11$ mice from two independent experiments. Source data are provided as a Source Data File

via a central bulging from the antigen binding cleft or occasionally via amino- or carboxy-terminal extensions from the MHCI groove ${ }^{25,27}$. Structural analysis of TCRs binding long peptides in complex with MHCI show that TCRs can achieve pMHCI recognition using a variety of strategies, including flattening the bulged peptide to increase MHCI contact, or sitting atop the peptide making minimal MHCI contact ${ }^{28}$. Collectively, given their prevalence and the demonstrated ability of $\mathrm{T}$ cells to recognize long peptides, our data further suggest that proteomewide discovery-based approaches should now be utilized to obtain a comprehensive representation of the peptidome.
Whilst we have conceivably captured all available $\mathrm{H}-2 \mathrm{D}^{\mathrm{b}}$ and $\mathrm{K}^{\mathrm{b}}$ complexes from cells through immunoprecipitation, there is potentially some bias in peptide identification. For example, $\mathrm{C}_{18}$ chromatography may miss overly hydrophilic or hydrophobic sequences and, due to the stochastic nature of conventional MS modalities for peptide isolation and fragmentation, coupled to protein-centric search algorithms, we may fail to detect and assign peptides of lower abundance, poor ionization, or where ambiguous spectra have been acquired ${ }^{29}$. It is also conceivable that a fraction of the viral repertoire is presented through proteasome-catalyzed peptide splicing, an area that requires 


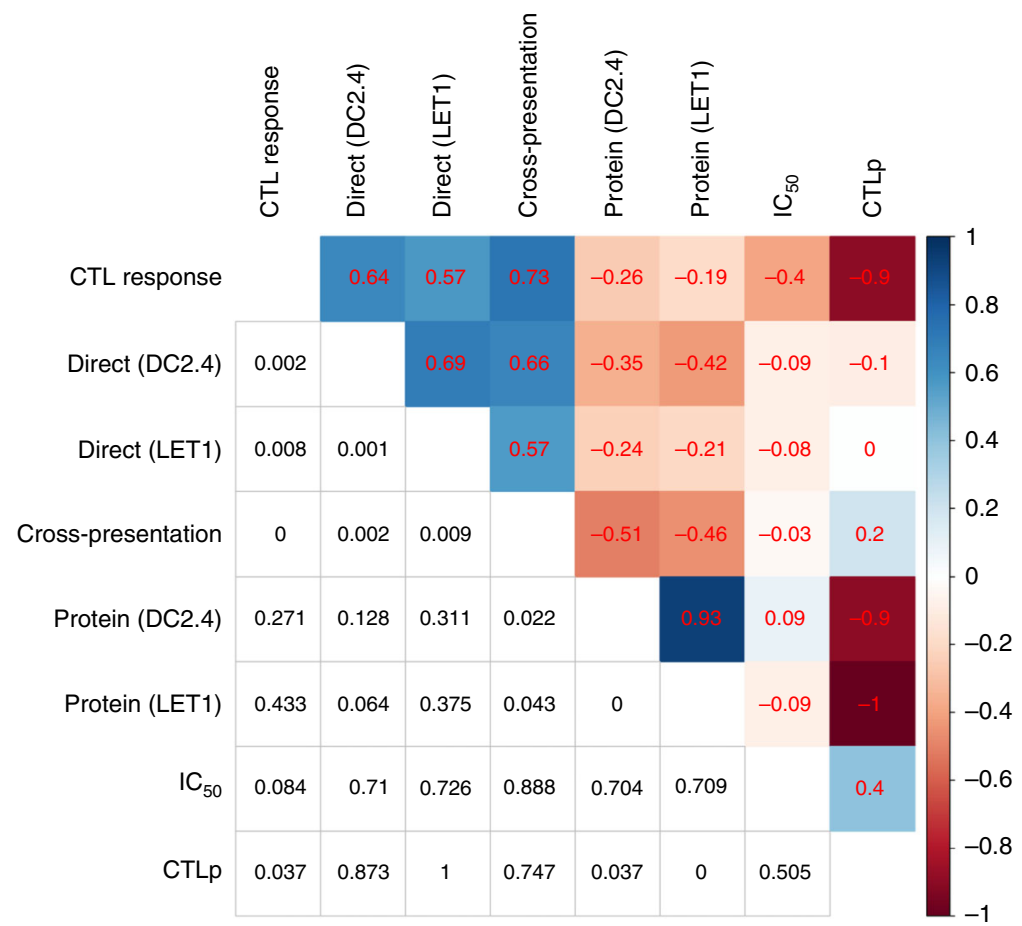

b
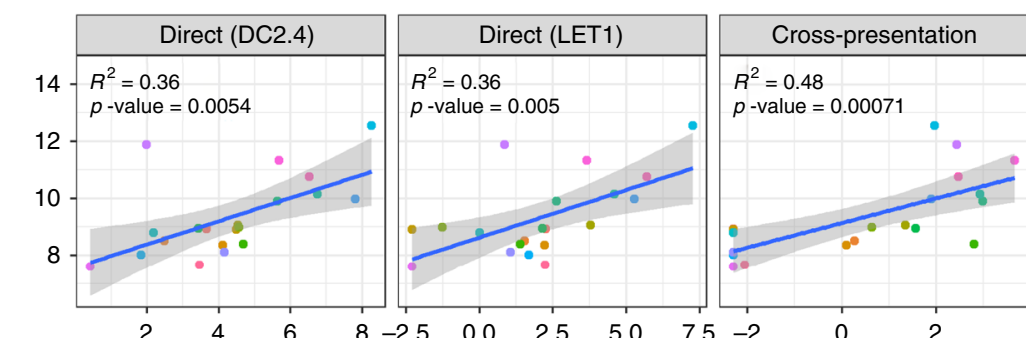

- $\mathrm{HA}_{304-311} \mathrm{~K}^{\mathrm{b}}$

- $\mathrm{HA}_{308-316} \mathrm{D}^{\mathrm{b}}$

- $\mathrm{HA}_{389-399} \mathrm{D}^{\mathrm{b}}$

- $\mathrm{HA}_{402-409} \mathrm{~K}^{\mathrm{b}}$

- $\mathrm{HA}_{41-49} \mathrm{D}^{\mathrm{b}} / \mathrm{K}^{\mathrm{b}}$

- $\mathrm{M} 1_{128-135} \mathrm{~K}^{\mathrm{b}}$

- $M 1_{207-216} \mathrm{D}^{\mathrm{b}}$

- $\mathrm{M1}_{227-237} \mathrm{D}^{\mathrm{b}}$

- $N A_{181-190} D^{b}$
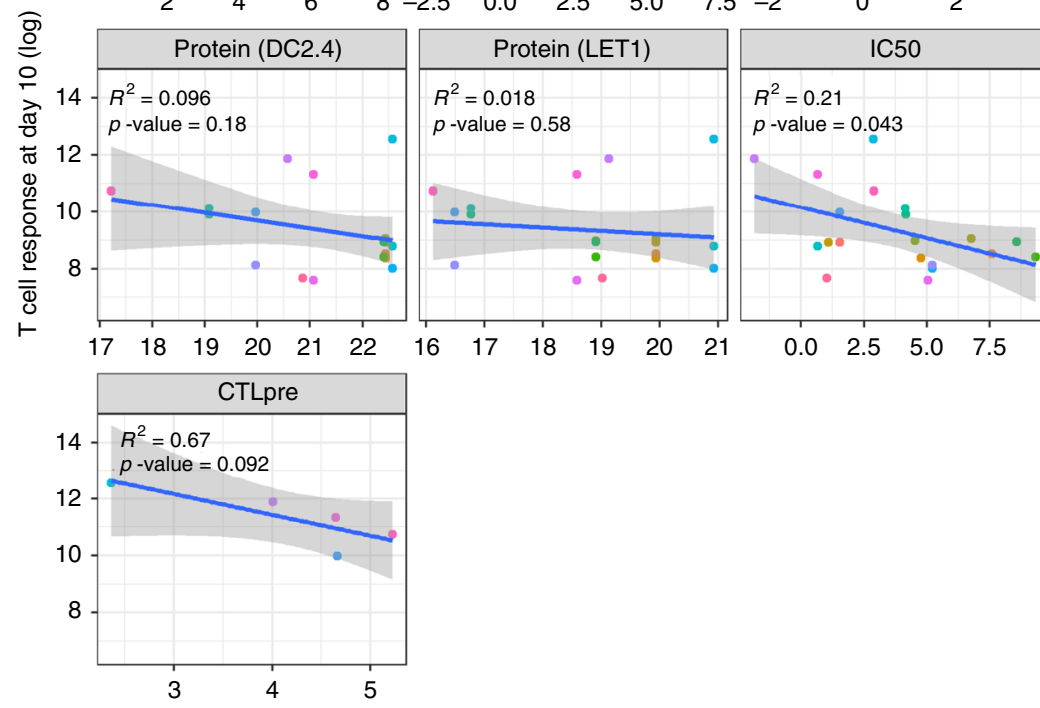

- $N A_{181-191} D^{b}$

- $\mathrm{NP}_{36-43} \mathrm{~K}^{\mathrm{b}}$

- $N P_{366-374} D^{b}$

- $\mathrm{NP}_{55-63} \mathrm{D}^{\mathrm{b}}$

- NS2 ${ }_{114-121} \mathrm{~K}^{\mathrm{b}}$

- $\mathrm{NS}{ }_{8-16} \mathrm{~K}^{\mathrm{b}}$

- $\mathrm{PA}_{224-233} \mathrm{D}^{\mathrm{b}}$

- $\mathrm{PB} 1_{653-660} \mathrm{~K}^{\mathrm{b}}$

- $\mathrm{PB} 1_{703-711} \mathrm{~K}^{\mathrm{b}}$

- PB1-F2 ${ }_{62-70} \mathrm{D}^{b}$

- $\mathrm{PB} 2{ }_{227-234} \mathrm{~K}^{\mathrm{b}}$

Value of variable (log)

Fig. 6 Analysis of parameter contribution to $\mathrm{CD}^{+}$T-cell response hierarchy. a Correlations as assessed through spearman rank correlation test between all variables. Spearman rank correlation coefficient is shown in the upper diagonal and associated $p$ value (not adjusted for multiple comparison) in the lower diagonal. Color coding indicates strength of positive (blue) or negative (red) correlation between specific variables. Note that because the contribution of $\mathrm{HA}_{41-49}$ bound to $\mathrm{H}-2 \mathrm{D}^{\mathrm{b}}$ or $\mathrm{H}-2 \mathrm{~K}^{\mathrm{b}}$ could not be distinguished for $\mathrm{CTL}$ response, the abundance of $\mathrm{HA} 41-49$ bound to $\mathrm{H}-2 \mathrm{D}^{\mathrm{b}}$ and $\mathrm{H}-2 \mathrm{~K}^{\mathrm{b}}$ have been added for each of the presentation modalities to yield a single value. $\mathbf{b}$ Linear correlations between log-transformed outcome (CTL response magnitude at day 10) and log-transformed predictor variables. For each variable, we took the mean of all measurements before log transformation. $R^{2}$ values are shown for the performance of the model on the actual data used to fit the model. CTLp frequencies for five epitopes taken from ref. 22 
future investigation now that accessible algorithms are available ${ }^{30}$

In this study we comprehensively characterize epitope presentation during direct and cross-presentation and demonstrate its influence on CTL immunodominance hierarchies after IAV infection. This builds on a previous study that has shown that CTL precursor frequency fails to predict the magnitude of the ensuing immune response ${ }^{22}$, making this an ideal model in which to define the impact of epitope abundance on antigenicity and CTL response magnitude. Following, we highlight several important findings that arise from this direct analysis of antigenicity and the implications for CTL recruitment and expansion during infection. Firstly, we observed that directly infected cells show the same rank order of epitope presentation and abundance despite their tissue of origin. Given that DC2.4 cells express immunoproteasome subunits ${ }^{31}$, this challenges the notion that the immunoproteasome generates a unique repertoire of MHCIbinding peptides to the constitutive proteasome by virtue of unique cleavage site specificity ${ }^{32-34}$. Our findings support later studies, which showed a positive effect of immunoproteasome on the abundance of antigenic peptides, but little evidence for the generation of a qualitatively distinct peptide repertoire ${ }^{35,36}$. Secondly, our mass-spectrometry-based approach identified a number of new IAV peptides that were all immunogenic in at least one mouse, and that for many subdominant epitopes there was a private response where recruitment of these CTL specificities into the immune repertoire appears to be more stochastic than the responses to the more dominant $\mathrm{T}$-cell determinants. The most plausible explanation for poor or sporadic responses despite detectable epitope presentation is a lack of available naïve $T$ cells. So-called holes in the $\mathrm{T}$-cell repertoire have been attributed, in part, to the deletion of cross-reactive $\mathrm{T}$ cells due to excessive similarity to self-peptides ${ }^{37}$. Alternatively, some epitopes elicit poor T-cell responses despite a large number of available naïve $\mathrm{T}$ cells. In this case, the subdominance of the response may be a consequence of poor naïve T-cell quality, due either to a low affinity TCRs ${ }^{38}$ or noncanonical TCR-pMHC interactions that are incapable of driving robust signaling ${ }^{39}$. Such observations highlight the need to rethink how we define immunogenicity and reflect the complex nature of the immune response that are not uniform even in syngeneic experimental systems. Thirdly, we observed that while direct presentation yielded peptide abundances that spanned three orders of magnitude, the levels of cross-presented IAV-derived epitopes were much more uniform. This suggests that cross-presentation normalizes antigen presentation, providing a niche for $\mathrm{T}$-cell priming that facilitates the expansion of $\mathrm{T}$-cell clonotypes on a level playing field with respect to epitope abundances. Finally, and remarkably, when comparing direct versus cross-presentation we observed that although optimal presentation of $\mathrm{NP}_{366-374}$ was driven by direct presentation, the unique capacity of cross-presentation to drive high-level display of $\mathrm{PA}_{224-233}$ was associated with its immunodominant status. This was particularly striking in light of the exceedingly poor presentation of $\mathrm{PA}_{224-233}$ via direct presentation (ranking 19th of 21 peptides). The disparate behavior of these two immunodominant epitopes highlights the difficulty in predicting CTL response magnitude and confounds attempts to model the evolution of viral immunity.

Previous studies have indicated that the characteristics of antigens that are efficiently cross- versus directly presented are contrasting-short-lived, unstable cytosolic proteins are optimally presented via the direct route, while more stable forms of antigen, such as cell-associated proteins, are preferred for crosspresentation $^{40-42}$. Evidence for this comes from minigene expression of three IAV-derived $\mathrm{H}-2 \mathrm{D}^{\mathrm{b}}$-binding peptides, $\mathrm{NP}_{366-374}, \mathrm{PA}_{224-233}$, and PB1-F2 ${ }_{62-70}$, which demonstrated the unique capacity of the $\mathrm{PA}_{224-233}$ peptide to be retained as a longlived cytosolic pool of peptide that was able to sustain presentation for hours after termination of protein synthesis ${ }^{43}$. Collectively, our findings go some way in demystifying the relative contributions of direct and cross-presentation by demonstrating that peptides largely have access to both pathways. However, our data also support the notion that distinct peptide characteristics can markedly favor cross-presentation over direct presentation, and such distinctions can have major effects on the CTL response hierarchy.

In the current analysis of IAV infection, in contrast to vaccinia virus (VACV) infection of the same DC2.4 cell line ${ }^{4}$, we noted only minor variation in the kinetics of protein expression and no obvious correlation between that and the presentation kinetics of directly presented peptides sourced from those proteins. Of course, VACV, unlike IAV, is a large virus that exhibits temporal regulation of protein expression, which is likely to more easily facilitate the observation of associations between protein expression and epitope presentation that were not detected here. We did observe rapid (within $30 \mathrm{~min}$ ) presentation of epitopes derived from relatively abundant viral structural proteins (M, NA, HA), that were likely derived from pre-existing viral proteins rather than de novo production ${ }^{44}$. For later timepoints, $(\geq 3 \mathrm{hpi})$ the peak presentation of all peptides either preceded or was coincident with peak protein expression, suggesting that antigen presentation is linked with the translation of newly synthesized polypeptides. This would be consistent with any mechanism that allows for the sampling of newly translated proteins, including the disposal of defective products of translation or those that fail to achieve their final function in the viral lifecycle ${ }^{45}$. This is also supported by other studies demonstrating the rapid presentation of peptides after translation, and overall poor correlation between pMHCI levels and protein turnover ${ }^{4,46}$.

Peptide affinity for MHC has been shown in several systems, including VACV and lymphocytic choriomeningitis virus (LCMV), to correlate with the immunogenicity of pMHC during infections ${ }^{47,48}$. The elevated affinity is typically thought to increase the abundance of pMHC complex on the cell surface. Surprisingly, and in accordance with our recent findings for $\mathrm{VACV}^{18}$, our data revealed that the strong correlation between peptide affinity for MHCI (as measured by $\mathrm{IC}_{50}$ ) and $\mathrm{T}$-cell response magnitude occurred independently of epitope abundance. This is exemplified by the similar relative levels of the $\mathrm{HA}_{41-49}$ peptide presented on $\mathrm{H}_{2} \mathrm{D}^{\mathrm{b}}$ and $\mathrm{K}^{\mathrm{b}}$, following both direct and cross-presentation, despite this peptide exhibiting a substantially greater affinity for $\mathrm{K}^{\mathrm{b}}$. Additionally, the affinities of the $\mathrm{NP}_{366-374}$ and $\mathrm{PA}_{224-233}$ peptides for $\mathrm{H}_{2} \mathrm{D}^{\mathrm{b}}$ were the highest observed, corresponding with their immunodominant response status, but not with their differential abundance following direct presentation. Thus, in the absence of a notable effect on epitope abundance, it is possible that a relatively low affinity peptide/ MHC interaction, under the tensile force that is characteristic of agonistic TCR-pMHCI recognition ${ }^{49}$, leads to unstable interactions between the TCR and pMHC that result in suboptimal Tcell activation. It is also possible that peptide affinity for MHC primarily influences the longevity of pMHC complexes, which is also proposed to be a key indicator of antigenicity 50,51 , independently of the relative abundance of those complexes at a given timepoint.

The relevance of this study to the immune $\mathrm{CD} 8^{+} \mathrm{T}$-cell responses in humans should be highlighted, especially since human responses to many pathogens, and IAV in particular, reflect recall, rather than primary, responses. Nonetheless, humans must acquire T-cell immunity to viruses, and the primary CTL response to the initial exposure event establishes a framework from which an individual's capacity to respond to 
virus rechallenge thereafter is defined. For example, studies suggest that repeated exposures to the same virus tend to focus responses that were established following primary infection ${ }^{52,53}$, and that in some cases pre-existing memory populations may detrimentally impact subsequent $\mathrm{CD} 8^{+}$T-cell responses ${ }^{54,55}$. Thus, an understanding of the key contributors to antigenicity and immunodominance in primary $\mathrm{CD} 8^{+} \mathrm{T}$-cell responses is imperative for a comprehensive understanding of both primary and recall $\mathrm{CD} 8^{+} \mathrm{T}$-cell responses in humans. Certainly, characteristics of mouse and human antiviral $\mathrm{CD}^{+}{ }^{+} \mathrm{T}$-cell responses (reproducible immunogenicity and immunodominance in MHCmatched individuals) are similar, and direct analyses of epitope presentation are becoming highly feasible in human cells $s^{56}$. Such studies will ultimately elucidate whether similar mechanisms drive CTL immunodominance in the human setting.

In summary, our study provides new insights into the mechanisms by which antigen presentation influences CTL response magnitude after infection, with both direct and crosspresentation making pivotal contributions to distinct epitopespecific CTL responses. Such information, in conjunction with further studies relating the direct quantitation of epitope abundance to immune outcomes, are essential for the understanding and informed development of vaccines and immunotherapies targeting T-cell responses.

\section{Methods \\ Cell lines. The two murine cell lines used in direct infection were DC2.4 ${ }^{10}$, a DC- like cell line derived from B6 mice (kindly provided by Dr. Ken Rock, University of Massachusetts, Worcester, MA), and LET1 cells, a type I lung epithelial cell line derived from $\mathrm{B} 6$ mice $^{11}$. The cell lines used in cross-presentation were the human adenocarcinomic alveolar basal epithelial A549 cells (ATCC \#CCL-185) and the murine CD8 $\alpha^{+}$Mutu DC cells ${ }^{16}$ (kindly provided by Dr. Hans Acha-Orbea, University of Lausanne, Epalinges, Switzerland). All the cells were cultured at $37^{\circ} \mathrm{C}$ and in $5 \% \mathrm{CO}_{2}$ in recommended growth medium (purchased from Life Tech- nologies) supplemented with $10 \%$ fetal bovine serum (FBS), $50 \mathrm{IU} / \mathrm{ml}$ penicillin, 50 $\mu \mathrm{g} / \mathrm{ml}$ streptomycin and $2 \mathrm{mM}$ L-glutamine. DC2.4, LET1 and A549 cells were cultured in DMEM. Mutu cells were grown in IMDM supplemented with Gluta- MAX $^{\text {su. }}$. Murine EL-4 thymoma cell lines were maintained in RPMI-1640 supple- mented with $10 \%$ fetal FBS, $50 \mathrm{IU} / \mathrm{ml}$ penicillin, $50 \mu \mathrm{g} / \mathrm{ml}$ streptomycin and $2 \mathrm{mM}$ L-glutamine (RF-10) and EG7, a subclone of EL-4 transfected with ovalbumin (OVA) gene ${ }^{57}$, was maintained in RF-10 supplemented with $500 \mu \mathrm{g} / \mathrm{ml} \mathrm{G418}$ (Invitrogen).}

Mice and viruses. $\mathrm{C} 57 \mathrm{Bl} / 6\left(\mathrm{~B} 6, \mathrm{H}-2^{\mathrm{b}}\right) \mathrm{WT}$ mice and OT- 1 transgenic mice expressing a TCR specific for the OVA $257-264$ SIINFEKL peptide in complex with $\mathrm{H} 2-\mathrm{K}^{\mathrm{b}}$ were housed in specific pathogen-free animal facility of the Department of Microbiology and Immunology, University of Melbourne (Victoria, Australia) or at the Animal Research Laboratories (ARL) at Monash University. Mice aged at 6-12 weeks and PR8 H1N1 IAV (A/Puerto Rico/8/34) and PR8-OVA IAV ${ }^{17}$ were used in this study. All animal experimentation was conducted following the Australian National Health and Medical Research Council Code of Practice for the Care and Use of Animals for Scientific Purposes guidelines for housing and care of laboratory animals and performed in accordance with Institutional regulations after pertinent review and approval by the University of Melbourne and Monash University Animal Ethics Committees.

Synthetic peptides. Isotope-labeled peptides ( $>90 \%$ purity) were purchased from Mimotopes Pty Ltd (Clayton, Victoria, Australia) and dissolved in 100\% (v/v) dimethyl sulfoxide or $20 \sim 30 \%$ (v/v) ACN according to the manufacturer's instructions. The concentration of each peptide was determined using a Direct Detect $^{\circledast}$ Infrared Spectrometer (Merck, Germany).

Direct infection of cells. DC2.4 or LET1 cells were allowed to grow to $80-90 \%$ confluence in T175 flasks and harvested by trypsinisation. Cells $\left(\sim 1 \times 10^{8}\right)$ were washed and mock- or IAV-infected at a MOI of 5 at $37^{\circ} \mathrm{C}$ for $1 \mathrm{~h}$. The cells were then incubated for a further $7 \mathrm{~h}$ at $37^{\circ} \mathrm{C}$ with gentle rolling, and counted. Cells were washed, snap frozen and stored at $-80^{\circ} \mathrm{C}$.

Infection efficiency assay. At 8 hpi IAV or mock-infected DC2.4 or LET1 were fixed, permeabilized and stained with fluorescein isothiocyanate (FITC)-conjugated anti-influenza A nucleoprotein (NP) monoclonal antibody (D67J, eBioscience, San Diego, CA) for $30 \mathrm{~min}$ at $4^{\circ} \mathrm{C}$, followed by flow cytometric acquisition on a
FACSCanto (BD Biosciences, Oxford, UK) and analysis using FlowJo software (Tree Star Inc, Ashland, OR).

Intracellular cytokine staining. Lymphocytes were obtained from the pneumonic lung by bronchoalveolar lavage (BAL) and adherent cells were removed by incubating on plastic for $1 \mathrm{~h}$ at $37^{\circ} \mathrm{C}$. Single-cell preparations of spleen were enriched for CD8 T cells by panning on tissue culture plates coated previously with AffiniPure goat anti-mouse IgG + IgM $(\mathrm{H}+\mathrm{L})$ (Jackson ImmunoResearch Labs). CD8 + T-cell responses to each candidate epitope were tested via intracellular cytokine staining. Enriched lymphocytes from spleens or bronchoalveolar lavage of mice infected 10 days previously with IAV were incubated with $10 \mathrm{U} / \mathrm{ml}$ IL-2 (Roche) and $1 \mu \mathrm{g} / \mathrm{ml}$ Golgi-plug (BD Biosciences) in the presence or absence of $1 \mu \mathrm{M}$ synthetic peptide in 96 -well plates and cultured for $5 \mathrm{~h}$ at $37^{\circ} \mathrm{C}$ and $5 \% \mathrm{CO}_{2}$. Cells were then stained for surface expression of CD8 $\alpha$ and intracellular IFN- $\gamma$ and TNF. Data was acquired by flow cytometry (FACSCanto, BD Biosciences) and analysis was performed using Flowjo version 9.6 (FlowJo LLC, Ashland). Single viable live $\mathrm{CD}^{+}$lymphocytes were gated for analysis (Supplementary Fig. 7). A response was deemed positive if the test response (with background subtracted) was equal to or greater than $2 \times$ the average background values.

In vitro cross-presentation. A549 cells (antigen donor cells) were mock-infected or infected with IAV virus or IAV-OVA virus $(\mathrm{MOI}=10)$ for $10 \mathrm{~h}$ prior to $\gamma$ irradiation $(50 \mathrm{~Gy})$ to inhibit the proliferation of viruses and induce apoptosis of the cells. After washing, the irradiated cells were incubated with Mutu cells $\left(\mathrm{GFP}^{+}\right)$ at a ratio of 1:1 or 1:2 in the presence of $500 \mathrm{nM} \mathrm{CpG}$ oligodeoxynucleotides (InvivoGen) at $37^{\circ} \mathrm{C}$ and harvested at the designated time. For preliminary analysis of cross-presentation, the Mutu cells were then co-cultured with VPD450-labeled OT-1 CD8 ${ }^{+} \mathrm{T}$ cells at ratio of $1: 1$ at $37^{\circ} \mathrm{C}$ for $24 \mathrm{~h}$. OT-1 T-cell proliferation was assessed based on the VPD450 dye dilution in $\mathrm{CD}^{+} \mathrm{T}$ cells. Alternatively, the Mutu cells were stained with monoclonal 25-D1.16 antibody, specific for the $\mathrm{H}-2 \mathrm{~K}^{\mathrm{b}}$ bound peptide $\mathrm{OVA}_{257-264}$ (SIINFEKL), followed by a PE-conjugated anti-mouse IgG antibody (BD Biosciences), and analyzed by flow cytometry.

Purification of $\mathbf{M H C l}$-peptide complexes. Frozen cell pellets of murine cells (DC2.4s, LET1 or A549/Mutu cells) were lysed in $5 \mathrm{ml}$ of lysis buffer containing 50 $\mathrm{mM}$ Tris $\mathrm{pH}$ 8.0, $150 \mathrm{mM} \mathrm{NaCl}, 0.5 \%$ IGEPAL and protease inhibitors. The lysates were incubated at $4{ }^{\circ} \mathrm{C}$ for $1 \mathrm{~h}$ under rotation and centrifuged at $16,000 \times g$ for 10 min. After centrifugation, the MHC/peptide in the supernatant were captured sequentially by immunoaffinity purification using columns containing protein A sepharose (GE Healthcare) conjugated to firstly Y-3 (anti-H-2Kb) and then 28-14$8 \mathrm{~s}\left(\right.$ anti-H-2D $\mathrm{D}^{\mathrm{b}}$ ) monoclonal antibody ${ }^{58}$. The bound complexes were then eluted with $10 \%$ acetic acid and mixed with 50-200 fmol of each isotopic peptide. The mixture of peptides and dissociated MHCI molecules were further fractioned on a C18 reverse-phase column $(5 \mu \mathrm{m}, 50 \times 4.6 \mathrm{~mm}$ I.D., Chromolith Speed Rod, Merck) on an ÄKTAmicro HPLC system (GE Healthcare) across an increasing gradient of buffer B ( $80 \%$ acetonitrile, $0.1 \%$ TFA in water) at a constant flow rate of $1 \mathrm{ml} / \mathrm{min}$. Fractions were vacuum concentrated (Labconco Centrivap) and resuspended in $0.1 \%$ formic in water to a volume of $20 \mu \mathrm{l}$ prior to mass spectrometry analysis.

Identification of viral peptides by IDA mass spectrometry. Peptide fractions were analyzed by LC-MS/MS with trapping and separation using an Eksigent nanoLC-Ultra 2D plus system (SCIEX) combined with a cHiPLC-nanoflex system (SCIEX) in trap-elute mode (trap column: $200 \mu \mathrm{m} \times 0.5 \mathrm{~mm}$ ChromXP C18-CL 3 $\mu \mathrm{m}, 120 \AA \AA$; analytical column: $75 \mu \mathrm{m} \times 15 \mathrm{~cm}$ ChromXP C18-CL $3 \mu \mathrm{m}, 120 \AA$ ). Separation was achieved at a flow rate of $300 \mathrm{nl} / \mathrm{min}$ with increasing linear concentrations of buffer B ( $80 \%$ acetonitrile, $0.1 \%$ formic acid in water). Acquisition of spectra was by a TripleTOF ${ }^{\circledR} 5600^{+}$(SCIEX) mass spectrometer through an uncoated silica PicoTip ${ }^{\text {wa }}$ nano electrospray emitter (New Objective Woburn, MA) with an ion spray voltage of $2300 \mathrm{~V}$ in positive ion mode. The MS analysis was performed in Information Dependent mode (IDA) using the following parameters: $200 \mathrm{~ms}$ of MS1 scan acquired from 200 to $1800 \mathrm{Da} \mathrm{m} / \mathrm{z}$ followed by $150 \mathrm{~ms}$ MS/MS scan over an $\mathrm{m} / \mathrm{z}$ range of $60-1800 \mathrm{Da}$. Up to 20 of the most intense ions with a charge-state of +2 to +5 were selected for MS/MS per cycle if they exceeded 40 counts per second (cps), and then they were excluded for further analysis for $30 \mathrm{~s}$ after two occurrences. Data analysis was performed on ProteinPilot version 4.5 (SCIEX). An in-house database was used which contained protein sequences of Mus musculus, influenza H1N1 IAV-PR8 strain and proteins from the alternative open reading frames of IAV-PR8. The peptides generated from the software were exported into Microsoft Excel for further data analysis at a 5\% false discovery rate cut-off.

Identification of viral peptides by LC-MRM. LC-MRM was initially employed to detect peptides reported in previous studies. Initially, a list of viral peptides was generated by searching the open-source immune epitope database and analysis resource ${ }^{59}$. The design of MRM transitions for each peptide were aided by the Skyline software ${ }^{60}$. The positive double charged precursor ion and at least three single or double charged product ions ( $\mathrm{y}$ and $\mathrm{b}$ ions) for each peptide were selected. 
The collision energy (CE) and declustering potential (DP) was calculated automatically in Skyline according to the rolling collision energy equations used by the QTRAP $^{\circledR} 5500$ (SCIEX). The dwell time was set to $5 \mathrm{~ms}$ to ensure sufficient data points (at least eight) could be acquired across the chromatographic peak. The identification of peptides using LC-MRM MS was performed as follows: separation of the peptides was performed on the same Eksigent nanoLC system as described above; after online LC separation, the MS was operated in a nonscheduled MRM mode followed by an Enhanced Product Ion (EPI) scan triggered each cycle for the most intense MRM transition. The MRM transitions were acquired at unit resolution in the first and third quadrupoles (Q1 and Q3). In EPI scanning mode, rolling collision energy (CE) was applied to acquire fragment ion spectra for selected precursor ions. The results were then analyzed by Skyline.

Design of viral peptides MRMs for peptide quantification. The design of MRM transitions for the quantification of identified influenza peptides was performed as follows: initially, the predominant precursor ion of each peptide was selected by Q1 in EMS scanning mode and the product ion spectra were obtained in EPI scanning mode. At least four of the most intense precursor-product ion pairs for each peptide were chosen to generate MRM transitions. The CE for each transition was further optimized by ramping CE across a range around the instrument-predicted value. Two MRM methods were established: nonscheduled MRM and scheduled MRM, the latter for large numbers of transitions $(>500)$. In nonscheduled MRM mode, the dwell time for each transition was set to $5 \mathrm{~ms}$. In scheduled MRM mode, the transitions of each peptide were only acquired at the expected retention time using a $300 \mathrm{~s}$ MRM detection window and a target cycle time of $3 \mathrm{~s}$. An EPI scan was also conducted.

Analysis of $\mathbf{I C}_{\mathbf{5 0}}$. Classical competition assays to quantitatively measure peptide binding to the mouse class $\mathrm{I} \mathrm{H}-2 \mathrm{~K}^{\mathrm{b}}$ and $\mathrm{D}^{\mathrm{b}}$ molecules were based on the inhibition of binding of high affinity radiolabeled peptides to purified MHC molecules ${ }^{19}$. Briefly, $0.1-1 \mathrm{nM}$ of radiolabeled peptide was co-incubated at room temperature with purified MHC in the presence of a cocktail of protease inhibitors. Following a 2-day incubation, MHC-bound radioactivity was determined by capturing pMHCI complexes on Lumitrac 600 plates (Greiner Bio-one, Frickenhausen, Germany) coated with either the $\mathrm{Y} 3$ (anti-H-2 $\mathrm{K}^{\mathrm{b}}$ ) or $28-14-8 \mathrm{~s}$ (anti-H-2 $\mathrm{D}^{\mathrm{b}}, \mathrm{L}^{\mathrm{d}}$ and $\mathrm{D}^{\mathrm{q}}$ ) monoclonal antibodies, and bound cpm measured using the TopCount (Packard Instrument Co., Meriden, CT) microscintillation counter. The concentration of peptide yielding $50 \%$ inhibition of binding of the radiolabeled peptide was calculated and, under the conditions utilized, where [label $]<[\mathrm{MHC}]$ and IC50 $\geq$ $[\mathrm{MHC}]$, measured $\mathrm{IC}_{50}$ values are reasonable approximations of true $\mathrm{K}_{\mathrm{d}}{ }^{61}$. Each competitor peptide was tested at six different concentrations covering a 100,000fold range, and in three or more independent experiments. As a positive control, the unlabeled version of the radiolabeled probe was also tested in each experiment.

Relative quantitation of viral protein expression. Lysate from flow-through immunoprecipitation experiments was reduced through treatment with TCEP (tris (2-carboxyethyl)phosphine) at a final concentration of $5 \mathrm{mM}$ for $30 \mathrm{~min}$ at $60^{\circ} \mathrm{C}$. Protein extraction was carried out by loading the sample onto a filter-assisted sample preparation (FASP) column ${ }^{62}$, alkylating cysteine residues through treatment with $50 \mathrm{mM}$ iodoacetamide for $20 \mathrm{~min}$ at room temperature in the dark and digestion of proteins with trypsin (enzyme:protein ratio of $1: 100$ ) at $37^{\circ} \mathrm{C}$ overnight. Digested peptides were eluted from the column with $50 \mu \mathrm{l}$ of $0.5 \mathrm{M}$ sodium chloride and further purified by $\mathrm{C}_{18}$ tips (OMIX) prior to LC-MS analysis. For all runs, an online Eksigent nanoLC-Ultra 2D Plus was used, equipped with a cHiPLC-nanoflex system. A trap column $(200 \mu \mathrm{m} \times 0.5 \mathrm{~mm}$ ChromXP C18-CL 3 $\mu \mathrm{m} 120 \AA$ ) was used for sample loading at $5 \mu \mathrm{l} / \mathrm{min}$ in $100 \%$ buffer A, followed by an analytical column $(75 \mu \mathrm{m} \times 15 \mathrm{~cm}$ ChromXP C18-CL $3 \mu \mathrm{m}, 120 \AA$ ) operating at $300 \mathrm{nl} / \mathrm{min}$ under the following gradient conditions: $2-43 \%$ buffer B over $120 \mathrm{~min}$, $43-98 \%$ B over $1 \mathrm{~min}$, hold at $98 \%$ for $4 \mathrm{~min}$ and then a decrease back to $2 \%$ B over $1 \mathrm{~min}$, holding for another $9 \mathrm{~min}$ at $2 \% \mathrm{~B}$ until the end of the run. For SWATH-MS analysis of the DC2.4 infection timecourse, an initial spectral library of tryptic peptides was generated by subjecting each sample to data-dependent acquisition on a $5600^{+}$TripleTOF ${ }^{\circledR}$ system (SCIEX) using the following parameters: $200 \mathrm{~ms}$ MS1 scan acquisition from 200 to $1800 \mathrm{~m} / \mathrm{z}$ followed by $120 \mathrm{~ms}$ MS2 acquisition scan from 60 to $1800 \mathrm{~m} / \mathrm{z}$. Acquired spectra were searched against the combined IAV and mouse proteome database (Uniprot; March 2015) using ProteinPilot ${ }^{\text {ix }}$ (SCIEX) and the resulting combined search file used for spectral library generation in Skyline. For SWATH-MS acquisition, the following acquisition scheme was used: $250 \mathrm{~ms}$ MS1 scan across $300-1800 \mathrm{~m} / \mathrm{z}$, followed by 28 sequential SWATH windows of $25 \mathrm{Da}$ each (1 Da overlap) from 300 to $1000 \mathrm{~m} / \mathrm{z}$. For each window, MS2 spectra were acquired for $100 \mathrm{~ms}$ across a scan range of 100-1800 m/z.

For LFQ analysis across direct infection of DC2.4 and LET-1 cells, or crosspresentation in Mutu cells, data were obtained from a Q Exactive ${ }^{\mathrm{mw}}$ Plus (Thermo Scientific) mass spectrometer, coupled online with an RSLC nano-LC system (Ultimate 3000, Dionex). Tryptic peptide digests corresponding to $2 \mu \mathrm{g}$ of material were loaded onto an Acclaim PepMap 100 trap column $(100 \mu \mathrm{m} \times 2 \mathrm{~cm}$, nanoViper $\mathrm{C}_{18}, 100 \AA$ pore size; Thermo Scientific) in buffer A at a flow rate of $15 \mu \mathrm{l} / \mathrm{min}$. Peptides were separated across an RSLC PepMap 100 C18 nano column $(75 \mu \mathrm{m} \times$ $50 \mathrm{~cm}, 3 \mu \mathrm{m}, 100 \AA$ A pore size; Thermo Scientific) at a flow rate of $250 \mathrm{nl} / \mathrm{min}$ under the following gradient conditions: $0-2$ min hold at $2.5 \%$ buffer B, then $2.5-7.5 \% \mathrm{~B}$ from 2 to $3 \mathrm{~min}$, then $7.5-40 \%$ B from 3 to $123 \mathrm{~min}, 40-99 \%$ B from 123 to 128 min, hold at $99 \%$ B from 128 to $134 \mathrm{~min}$, then decrease of $99-2.5 \%$ B over $1 \mathrm{~min}$ followed by re-equilibration at $2.5 \% \mathrm{~B}$ for $20 \mathrm{~min}$ until the end of the run. The Q Exactive $^{\mathrm{m}}$ Plus was operated in data-dependent acquisition mode, with an MS1 scan acquired across a mass range of $375-1800 \mathrm{~m} / \mathrm{z}$ at a resolution of 70,000 at $200 \mathrm{~m} / \mathrm{z}$. Automatic Gain Control (AGC) target was set to a value of $3 \times 10^{6}$ and maximum ion injection time (IT) of $50 \mathrm{~ms}$. Dynamic exclusion was set to $20 \mathrm{~s}$. The 12 most intense multiply charged ions were sequentially isolated and fragmented in the octopole collision cell by higher-energy collisional dissociation (HCD) with the following parameters: 17,500 resolution, MS2 AGC target value of $2 \times 10^{5}$, normalized collision energy (NCE) of $27 \%$ and maximum IT of $120 \mathrm{~ms}$ and $1.8 \mathrm{~m} / \mathrm{z}$ isolation window. Data searching was carried out using MaxQuant ${ }^{12}$ (version 1.5.2.8) against a combined database of Mus musculus, Homo sapiens and influenza strain PR8 (all obtained from Uniprot; March 2015) and with results at 1\% FDR. LFQ minimum ratio count was set to two and matching between runs was enabled with a window of $0.7 \mathrm{~min}$. LFQ data were analyzed in Perseus ${ }^{63}$ (version 1.5.3.0).

Modeling and statistical analysis. Subset selection for the linear multivariable models was done with the mlr package ${ }^{64}$ in $\mathrm{R}$ using an exhaustive search over all sub-models and evaluating each sub-model by minimizing the mean squared error (MSE) on the test data through 100 times repeated cross-validation (tenfold, ten repeats) ${ }^{65}$. Model performance was reported as measured by the coefficient of determination $\left(R^{2}=1-\mathrm{MSE} / \mathrm{MST}\right.$, where MST is mean square total), evaluated on the hold-out dataset in cross-validation.

We also used several more complex and powerful machine-learning approaches that typically provide strong predictive performance ${ }^{65}$. These models were tuned using the same cross-validation approach and model performance assessment as for the linear model. Further details are provided in the Supplementary Information. For the linear model, we assessed the importance of each predictor remaining in the best-performing model using the PMVD method described in ref. ${ }^{66}$ using the relaimpo package ${ }^{67}$. Statistical analysis on scatter plots was carried out using GraphPad Prism software. Differences were considered significant when $p$ values were $<0.05$. Spearman rank correlation tests were performed in $\mathrm{R}$ using the cor and cor.test functions.

Reporting summary. Further information on research design is available in the Nature Research Reporting Summary linked to this article.

\section{Data availability}

Immunopeptidomics and proteomics datasets analyzed in this study have been deposited to the ProteomeXchange Consortium via the PRIDE partner repository ${ }^{68}$ with the dataset identifiers PXD012728 (MHC and SWATH data) and PXD012776 (LFQ data). MRM data have been made available on the The PeptideAtlas Project ${ }^{69}$ at the following address: http://www.peptideatlas.org/PASS/PASS01317. Data underlying Fig. 5 and Supplementary Fig. 6 are provided as a Source Data File. Data underlying Figs. 1-4 and Supplementary Figs. 4 and 5 are included as Supplementary Data Files 1 and 2. All other data are available from the corresponding authors upon reasonable requests.

Received: 18 December 2018 Accepted: 24 May 2019

Published online: 28 June 2019

\section{References}

1. Luciani, F., Sanders, M. T., Oveissi, S., Pang, K. C. \& Chen, W. Increasing viral dose causes a reversal in CD8 $+\mathrm{T}$ cell immunodominance during primary influenza infection due to differences in antigen presentation, $\mathrm{T}$ cell avidity, and precursor numbers. J. Immunol. 190, 36-47 (2013).

2. La Gruta, N. L. et al. A virus-specific CD8+ T cell immunodominance hierarchy determined by antigen dose and precursor frequencies. Proc. Natl. Acad. Sci. USA 103, 994-999 (2006).

3. Croft, N. P., Purcell, A. W. \& Tscharke, D. C. Quantifying epitope presentation using mass spectrometry. Mol. Immunol. 68, 77-80 (2015).

4. Croft, N. P. et al. Kinetics of antigen expression and epitope presentation during virus infection. PLoS Pathog. 9, e1003129 (2013).

5. Tscharke, D. C., Croft, N. P., Doherty, P. C. \& La Gruta, N. L. Sizing up the key determinants of the CD8(+) T cell response. Nat. Rev. Immunol. 15, 705-716 (2015).

6. Thomas, P. G. et al. Hidden epitopes emerge in secondary influenza virusspecific CD8+ T cell responses. J. Immunol. 178, 3091-3098 (2007).

7. Vitiello, A. et al. Immunodominance analysis of CTL responses to influenza PR8 virus reveals two new dominant and subdominant Kb-restricted epitopes. J. Immunol. 157, 5555-5562 (1996). 
8. Zanker, D., Waithman, J., Yewdell, J. W. \& Chen, W. Mixed proteasomes function to increase viral peptide diversity and broaden antiviral CD8 + T cell responses. J. Immunol. 191, 52-59 (2013).

9. Zhong, W., Reche, P. A., Lai, C. C., Reinhold, B. \& Reinherz, E. L. Genomewide characterization of a viral cytotoxic T lymphocyte epitope repertoire. $J$. Biol. Chem. 278, 45135-45144 (2003).

10. Shen, Z., Reznikoff, G., Dranoff, G. \& Rock, K. L. Cloned dendritic cells can present exogenous antigens on both MHC class I and class II molecules. J. Immunol. 158, 2723-2730 (1997).

11. Rosenberger, C. M. et al. Characterization of innate responses to influenza virus infection in a novel lung type I epithelial cell model. J. Gen. Virol. 95, 350-362 (2014).

12. Cox, J. \& Mann, M. MaxQuant enables high peptide identification rates, individualized p.p.b.-range mass accuracies and proteome-wide protein quantification. Nat. Biotechnol. 26, 1367-1372 (2008).

13. Fiebiger, B. M., Moosmann, A., Behrends, U. \& Mautner, J. Mature proteins derived from Epstein-Barr virus fail to feed into the MHC class I antigenic pool. Eur. J. Immunol. 42, 3167-3173 (2012).

14. Dolan, B. P., Li, L., Takeda, K., Bennink, J. R. \& Yewdell, J. W. Defective ribosomal products are the major source of antigenic peptides endogenously generated from influenza A virus neuraminidase. J. Immunol. 184, 1419-1424 (2010).

15. GeurtsvanKessel, C. H. et al. Clearance of influenza virus from the lung depends on migratory langerin $+\mathrm{CD} 11 \mathrm{~b}-$ but not plasmacytoid dendritic cells. J. Exp. Med. 205, 1621-1634 (2008).

16. Steiner, Q. G. et al. In vivo transformation of mouse conventional CD8alpha + dendritic cells leads to progressive multisystem histiocytosis. Blood 111, 2073-2082 (2008).

17. Jenkins, M. R., Webby, R., Doherty, P. C. \& Turner, S. J. Addition of a prominent epitope affects influenza A virus-specific CD8+ T cell immunodominance hierarchies when antigen is limiting. J. Immunol. 177, 2917-2925 (2006).

18. Croft, N. P. et al. Most viral peptides displayed by class I MHC on infected cells are immunogenic. Proc. Natl. Acad. Sci. USA 116, 3112-3117 (2019).

19. Sidney, J. et al. Measurement of MHC/peptide interactions by gel filtration or monoclonal antibody capture. Curr. Protoc. Immunol. Chapter 18, Unit 18.3 (2013).

20. Assarsson, E. et al. A quantitative analysis of the variables affecting the repertoire of $\mathrm{T}$ cell specificities recognized after vaccinia virus infection. $J$ Immunol. 178, 7890-7901 (2007).

21. Sette, A. et al. The relationship between class I binding affinity and immunogenicity of potential cytotoxic T cell epitopes. J. Immunol. 153 , 5586-5592 (1994)

22. La Gruta, N. L. et al. Primary CTL response magnitude in mice is determined by the extent of naive $\mathrm{T}$ cell recruitment and subsequent clonal expansion. J. Clin. Invest. 120, 1885-1894 (2010).

23. Rist, M. J. et al. HLA peptide length preferences control CD8+ T cell responses. J. Immunol. 191, 561-571 (2013).

24. Stevens, J., Wiesmuller, K. H., Walden, P. \& Joly, E. Peptide length preferences for rat and mouse $\mathrm{MHC}$ class I molecules using random peptide libraries. Eur. J. Immunol. 28, 1272-1279 (1998).

25. Pymm, P. et al. MHC-I peptides get out of the groove and enable a novel mechanism of HIV-1 escape. Nat. Struct. Mol. Biol. 24, 387-394 (2017).

26. Andreatta, M. \& Nielsen, M. Bioinformatics tools for the prediction of T-cell epitopes. Methods Mol. Biol. 1785, 269-281 (2018).

27. Remesh, S. G. et al. Unconventional peptide presentation by major histocompatibility complex (MHC) class I allele HLA-A ${ }^{\star} 02: 01$ : breaking confinement. J. Biol. Chem. 292, 5262-5270 (2017).

28. Tynan, F. E. et al. A T cell receptor flattens a bulged antigenic peptide presented by a major histocompatibility complex class I molecule. Nat. Immunol. 8, 268-276 (2007).

29. Faridi, P., Purcell, A. W. \& Croft, N. P. In immunopeptidomics we need a sniper instead of a shotgun. Proteomics 18, el700464 (2018).

30. Faridi, P. et al. A subset of HLA-I peptides are not genomically templated: Evidence for cis- and trans-spliced peptide ligands. Sci. Immunol. 3, eaar3947 (2018).

31. Tu, L. et al. Critical role for the immunoproteasome subunit LMP7 in the resistance of mice to Toxoplasma gondii infection. Eur. J. Immunol. 39 , 3385-3394 (2009).

32. Driscoll, J., Brown, M. G., Finley, D. \& Monaco, J. J. MHC-linked LMP gene products specifically alter peptidase activities of the proteasome. Nature 365, 262-264 (1993).

33. Gaczynska, M., Rock, K. L., Spies, T. \& Goldberg, A. L. Peptidase activities of proteasomes are differentially regulated by the major histocompatibility complex-encoded genes for LMP2 and LMP7. Proc. Natl. Acad. Sci. USA 91, 9213-9217 (1994).
34. Toes, R. E. et al. Discrete cleavage motifs of constitutive and immunoproteasomes revealed by quantitative analysis of cleavage products. $J$ Exp. Med. 194, 1-12 (2001)

35. Mishto, M. et al. Proteasome isoforms exhibit only quantitative differences in cleavage and epitope generation. Eur. J. Immunol. 44, 3508-3521 (2014).

36. Zanker, D. \& Chen, W. Standard and immunoproteasomes show similar peptide degradation specificities. Eur. J. Immunol. 44, 3500-3503 (2014).

37. Nelson, R. W. et al. T cell receptor cross-reactivity between similar foreign and self peptides influences naive cell population size and autoimmunity. Immunity 42, 95-107 (2015).

38. Cukalac, T. et al. The influenza virus-specific CTL immunodominance hierarchy in mice is determined by the relative frequency of high-avidity T cells. J. Immunol. 192, 4061-4068 (2014).

39. Gras, S. et al. Reversed $\mathrm{T}$ cell receptor docking on a major histocompatibility class I complex limits involvement in the immune response. Immunity $\mathbf{4 5}$, 749-760 (2016).

40. Gutierrez-Martinez, E. et al. Cross-presentation of cell-associated antigens by MHC class I in dendritic cell subsets. Front. Immunol. 6, 363 (2015).

41. Norbury, C. C. et al. CD8+ T cell cross-priming via transfer of proteasome substrates. Science 304, 1318-1321 (2004).

42. Wolkers, M. C., Brouwenstijn, N., Bakker, A. H., Toebes, M. \& Schumacher, T. N. Antigen bias in T cell cross-priming. Science 304, 1314-1317 (2004).

43. Lev, A. et al. The exception that reinforces the rule: crosspriming by cytosolic peptides that escape degradation. Immunity 28, 787-798 (2008).

44. Ternette, N. et al. Early kinetics of the HLA class I-associated peptidome of MVA.HIV consv-infected cells. J. Virol. 89, 5760-5771 (2015)

45. Apcher, S. et al. Major source of antigenic peptides for the MHC class I pathway is produced during the pioneer round of mRNA translation. Proc. Natl. Acad. Sci. USA 108, 11572-11577 (2011).

46. Hassan, C. et al. Naturally processed non-canonical HLA-A*02:01 presented peptides. J. Biol. Chem. 290, 2593-2603 (2015).

47. Kotturi, M. F. et al. Naive precursor frequencies and MHC binding rather than the degree of epitope diversity shape CD8 + T cell immunodominance. $J$. Immunol. 181, 2124-2133 (2008).

48. Moutaftsi, M. et al. A consensus epitope prediction approach identifies the breadth of murine T(CD8+)-cell responses to vaccinia virus. Nat. Biotechnol. 24, 817-819 (2006).

49. Liu, B., Chen, W., Evavold, B. D. \& Zhu, C. Accumulation of dynamic catch bonds between TCR and agonist peptide-MHC triggers T cell signaling. Cell 157, 357-368 (2014).

50. Brooks, J. M., Colbert, R. A., Mear, J. P., Leese, A. M. \& Rickinson, A. B. HLA B27 subtype polymorphism and CTL epitope choice: studies with EBV peptides link immunogenicity with stability of the B27:peptide complex. J. Immunol. 161, 5252-5259 (1998).

51. Harndahl, M. et al. Peptide-MHC class I stability is a better predictor than peptide affinity of CTL immunogenicity. Eur. J. Immunol. 42, 1405-1416 (2012).

52. Busch, D. H., Pilip, I. \& Pamer, E. G. Evolution of a complex T cell receptor repertoire during primary and recall bacterial infection. J. Exp. Med. 188, 61-70 (1998)

53. Cukalac, T. et al. Reproducible selection of high avidity CD8+ T-cell clones following secondary acute virus infection. Proc. Natl. Acad. Sci. USA 111, 1485-1490 (2014)

54. Klenerman, P. \& Zinkernagel, R. M. Original antigenic sin impairs cytotoxic T lymphocyte responses to viruses bearing variant epitopes. Nature 394, 482-485 (1998).

55. Johnson, L. R., Weizman, O. E., Rapp, M., Way, S. S. \& Sun, J. C. Epitopespecific vaccination limits clonal expansion of heterologous naive $\mathrm{T}$ cells during viral challenge. Cell Rep. 17, 636-644 (2016)

56. Koutsakos, M. et al. Human CD8(+) T cell cross-reactivity across influenza A B and C viruses. Nat. Immunol. 20, 613-625 (2019).

57. Moore, M. W., Carbone, F. R. \& Bevan, M. J. Introduction of soluble protein into the class I pathway of antigen processing and presentation. Cell 54, 777-785 (1988).

58. Purcell, A. W., Ramarathinam, S. H. \& Ternette, N. Mass spectrometry-based identification of MHC-bound peptides for immunopeptidomics. Nat. Protoc. 14, 1687-1707 (2019).

59. Kim, Y. et al. Immune epitope database analysis resource. Nucleic Acids Res. 40, W525-W530 (2012).

60. MacLean, B. et al. Skyline: an open source document editor for creating and analyzing targeted proteomics experiments. Bioinformatics 26, 966-968 (2010).

61. Gulukota, K., Sidney, J., Sette, A. \& DeLisi, C. Two complementary methods for predicting peptides binding major histocompatibility complex molecules. $J$ Mol. Biol. 267, 1258-1267 (1997).

62. Wisniewski, J. R., Zougman, A., Nagaraj, N. \& Mann, M. Universal sample preparation method for proteome analysis. Nat. Methods 6, 359-362 (2009) 
63. Tyanova, S. et al. The Perseus computational platform for comprehensive analysis of (prote)omics data. Nat. Methods 13, 731-740 (2016).

64. Bischl, B. et al. mlr: machine learning in R. J. Mach. Learn. Res. 17, 1-5 (2016).

65. James, G., Witten, D., Hastie, T. \& Tibshirani, R. An Introduction to Statistical Learning: with Applications in R (Springer, New York, 2013).

66. Gromping, U. Variable importance in regression models. Wiley Interdiscip. Rev.: Comput. Stat. 7, 137-152 (2015).

67. Groemping, U. Relative importance for linear regression in R: The package relaimpo. J. Stat. Softw. 17, 1-26 (2006).

68. Perez-Riverol, Y. et al. The PRIDE database and related tools and resources in 2019: improving support for quantification data. Nucleic Acids Res. 47, D442-D450 (2019).

69. Desiere, F. et al. The PeptideAtlas project. Nucleic Acids Res. 34, D655-D658 (2006).

70. Oukka, M., Riche, N. \& Kosmatopoulos, K. A nonimmunodominant nucleoprotein-derived peptide is presented by influenza A virus-infected $\mathrm{H}-2 \mathrm{~b}$ cells. J. Immunol. 152, 4843-4851 (1994).

71. Townsend, A. R. et al. The epitopes of influenza nucleoprotein recognized by cytotoxic T lymphocytes can be defined with short synthetic peptides. Cell $\mathbf{4 4}$ 959-968 (1986).

72. Belz, G. T., Xie, W., Altman, J. D. \& Doherty, P. C. A previously unrecognized $\mathrm{H}-2 \mathrm{D}(\mathrm{b})$-restricted peptide prominent in the primary influenza A virusspecific $\mathrm{CD} 8(+) \mathrm{T}$-cell response is much less apparent following secondary challenge. J. Virol. 74, 3486-3493 (2000).

73. Belz, G. T., Xie, W. \& Doherty, P. C. Diversity of epitope and cytokine profiles for primary and secondary influenza a virus-specific CD8+ T cell responses. J. Immunol. 166, 4627-4633 (2001).

74. Chen, W. et al. A novel influenza A virus mitochondrial protein that induces cell death. Nat. Med. 7, 1306-1312 (2001).

\section{Acknowledgements}

We thank Stephen J. Turner and Jamie Rossjohn for critical reading of the manuscript, Lukasz Kedzierski and Claerwen Jones for technical assistance, and staff at Monash University flow cytometry, biomedical proteomics and animal core facilities. We thank Dr. Ken Rock for provision of DC2.4 cells and Dr. Acha-Orbea for provision of Mutu DCs. This work was supported by a Sylvia and Charles Viertel Senior Medical Research Fellowship, an Australian Research Council (ARC) Future Fellowship FT170100174, and a National Health and Medical Research Council (NHMRC) Program grant APP1071916 (to N.L.L.G.), an NHMRC Principal Research Fellowship APP1137739 (to A.W.P.), an NHMRC Senior Research Fellowship APP1104329 (to D.C.T.) and an NHMRC Project grant APP1084283 (to A.W.P., N.P.C., and D.C.T.). A.H. and P.G.T. were partially supported by NIH/NIAID grant U19AI117891.

\section{Author contributions}

Conceptualization N.L.L.G., A.W.P., N.P.C.; Methodology J.G., L.M.W., N.L.L.G., A.W.P., N.P.C., D.C.T., A.H., P.G.T., A.S.; Investigation J.G., T.W., X.Y.X.S., J.S., A.H.; Resources D.C.T., A.H., L.M.W., J.S., A.S., A.W.P., N.P.C., N.L.L.G.; Writing-original draft N.P.C., N.L.L.G., A.W.P.; Writing-review and editing N.P.C., N.L.L.G., A.W.P., P.G.T., A.H., D.C.T., L.M.W., A.S., J.S., T.W., J.G., X.Y.X.S.; Supervision N.L.L.G., N.P.C., A.W.P.; Funding acquisition A.W.P., N.P.C., D.C.T., N.L.L.G.

\section{Additional information}

Supplementary Information accompanies this paper at https://doi.org/10.1038/s41467019-10661-8.

Competing interests: The authors declare no competing interests.

Reprints and permission information is available online at http://npg.nature.com/ reprintsandpermissions/

Peer review information: Nature Communications thanks the anonymous reviewers for their contribution to the peer review of this work. Peer reviewer reports are available.

Publisher's note: Springer Nature remains neutral with regard to jurisdictional claims in published maps and institutional affiliations.

(c) (i) Open Access This article is licensed under a Creative Commons Attribution 4.0 International License, which permits use, sharing, adaptation, distribution and reproduction in any medium or format, as long as you give appropriate credit to the original author(s) and the source, provide a link to the Creative Commons license, and indicate if changes were made. The images or other third party material in this article are included in the article's Creative Commons license, unless indicated otherwise in a credit line to the material. If material is not included in the article's Creative Commons license and your intended use is not permitted by statutory regulation or exceeds the permitted use, you will need to obtain permission directly from the copyright holder. To view a copy of this license, visit http://creativecommons.org/ licenses/by/4.0/.

(C) The Author(s) 2019 